\title{
INFORME DE LA CEPAL SOBRE LA ECONOMIA CHILENA EN 1969
}

Presentamos en esta oportunidad un trabajo de singular interés, preparado por la Comisión Económica para América Latina sobre la actividad económica en Chile durante 1969.

El trabajo, que forma parte del Informe Anual sobre América Latina, consta de las siguientes secciones:

\section{A. Evolución de la actividad económica en 1969.}

1) Apreciaciones generales.

2) Comportamiento de los principales sectores de la producción.

3) Oferta y demanda globales.

4) Sector externo $y$ balanza de pagos.

5) Comportamiento de los precios en 1969 y algunas medidas anti-inflacionarias.

B. Aspectos sobresalientes de la política económica de Chile en los filtimos aăos.

1) La política del cobre.

2) La politica de chilenización.

3) La política de nacionalización pactada.

4) Valores retornados y no retornados.

C. La politica de Reforma Agraria.

1) Antecedentes.

2) Incorporación de tierras.

3) Formación de asentamientos y asignación de predios.

4) Ingresos y gastos de la Corporación de la Reforma Agraria.

El creciente interés de los intelectuales chilenos en torno a la necesidad de esclarecer, con espiritu critico, nuestra realidad nacional, justifica ampliamente la publicación de este estudio objetivo, cuyo análisis será de enorme utilidad en las cátedras universitarias. 


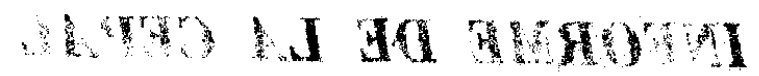

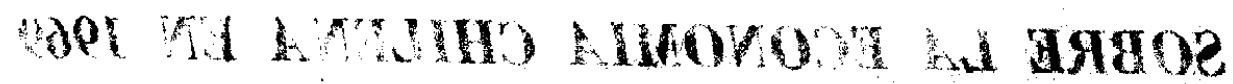

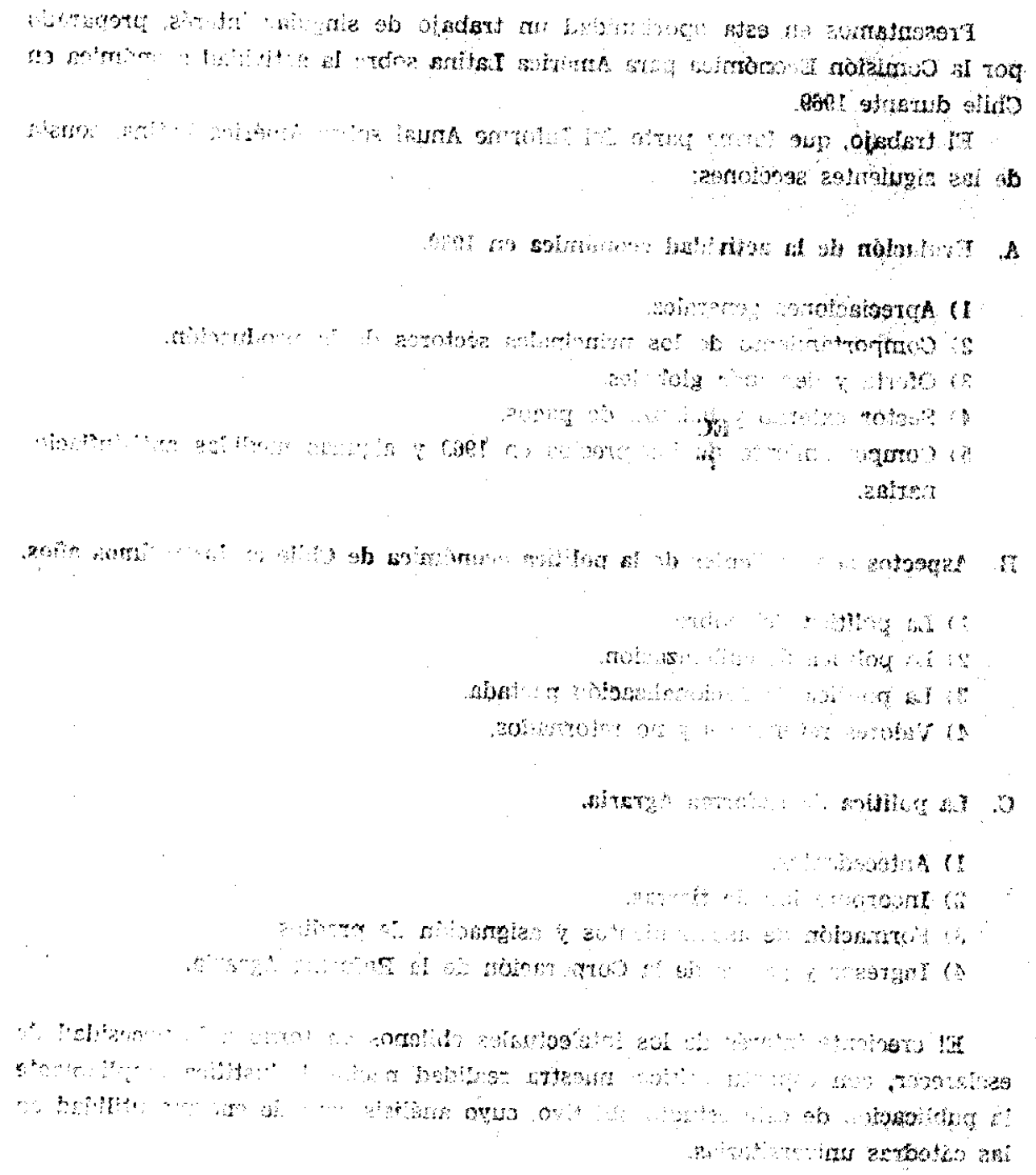

, 


\title{
INFORME DE LA CEPAL
}

\section{SOBRE LA ECONOMIA CHILENA EN 1969}

\author{
$\cdots \quad C H I L E$ \\ A.- EVOLUCION DE LA ACTIVIDAD ECONOMICA EN 1969 \\ 1.-Apreciaciones generales.
}

In 1969 la economfa chilena mostró cierta recuperación aupque manteniéndose dentro del pausado ritmo de crecimiento que caracterizó su evolución an los dos años anteriores. $\mathrm{El}$ producto interno bruto registra un aumento de $3 \%$, ligeramente superior al $2.7 \%$ del año 1968; sin embargo, este discreto aumento en el crecimiento del producto se tradujo en un incremento mucho mayor del ingreso real, al haber mejorado nuevamente el efecto de la relaciôn de precios de intercambio, como consecuencia de las cotizactones más elevadas obtenidas por el cobre en el mercado internacional. (Véase el cuadro II-63).

\section{CUADRO II-63}

CHILE: RITMO DE CRECIMIENTO DEL PRODUCTO TOTAL Y DEL INGRESO (Tasas anuales de crecimiento)

\begin{tabular}{|c|c|c|c|c|c|c|}
\hline Año & & & & $\begin{array}{l}\text { Producto int } \\
\text { bruto }\end{array}$ & terno & Ingreso \\
\hline 1961 & $\therefore$ & $\therefore$ & & 6.2 & $\therefore \quad$ & 6.3 \\
\hline 1962 & & " & & 5.0 & & 3,9 \\
\hline 1963 & & $\because$ & $\cdots$ & 4.7 & “ & $\therefore \quad \vdots \quad \therefore$ \\
\hline 1964 & $\therefore$ & & $\because \cdot$ & 4.2 & ' & $\therefore \quad \therefore \quad \cdots$ \\
\hline 1965 & $\because$ & & & 5.0 & & 6.5 \\
\hline 1966 & & $\because \because$ & & 7.0 & & $90:$ \\
\hline 1967 & $\therefore:$ & & $\because:{ }^{\prime}$ & 2.3 & & - \\
\hline 1968 & & & & 2.7 & & अ \\
\hline 1969 & : & & 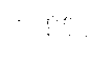 & 3.0 &. & $\therefore$ \\
\hline
\end{tabular}

Fuente: Años 1961-68: Presidencia de la República, Oefciria de Planiflcación Nacional, Cuentas Nacionales de Chile 1960-68.

Ano 1969: CEPAL, estimaciones preliminares a base de indicadores nacionales parciales.

Fn la evolución de los principales sectores productivos destated la reducción de la producción agropecuarta y el mayor crecimiento ocurrido en la minerla y 
en la industria manufacturera. (Véase el cuadro II-64). A su vez, is activided do

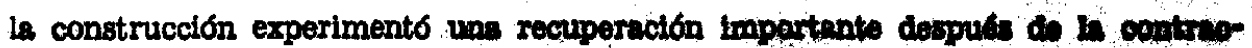

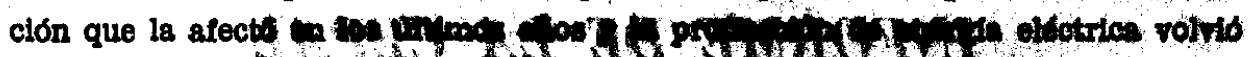

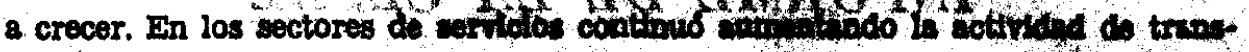

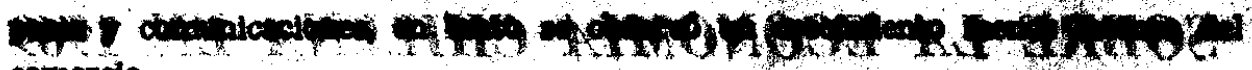
comercio.

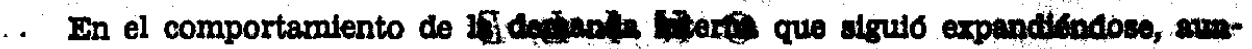

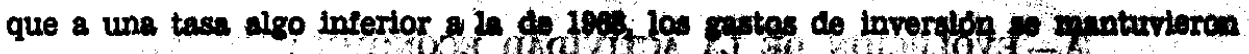

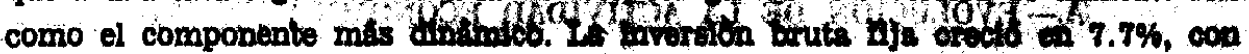

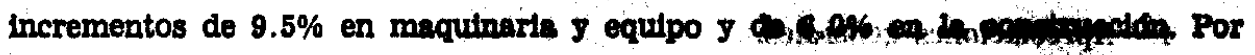
su parte, el consumo total crecio en $3.0 \%$, a consecuencia de un arrmento similar

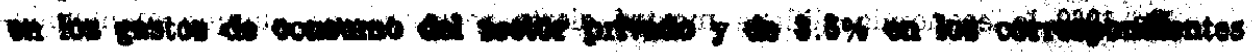
at govinive.

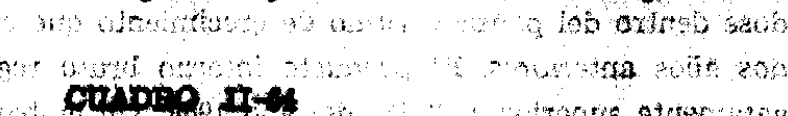

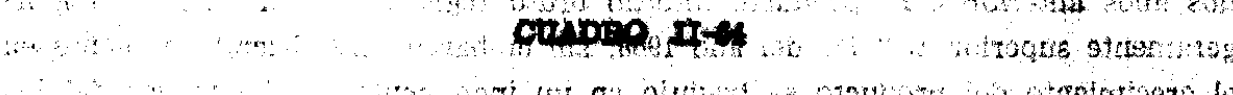

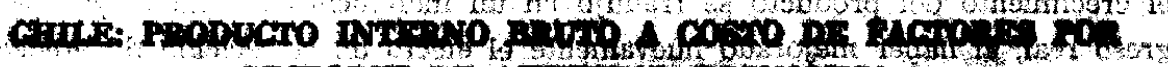

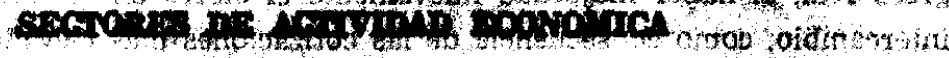

\begin{tabular}{|c|c|c|c|c|c|c|c|}
\hline & \multicolumn{4}{|c|}{ 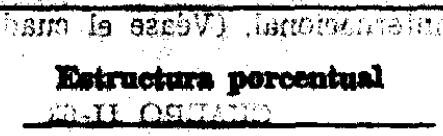 } & \multicolumn{3}{|c|}{ 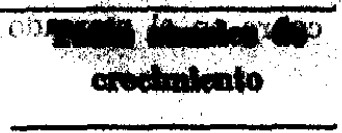 } \\
\hline & $19 \mathrm{~s}$ & Ins & ing & 1969 & & & to \\
\hline & $12.1^{\mathrm{T}}$ & 10.2 & 10.8 & 10.1 & 3.2 & 5.8 & -3.1 \\
\hline Almorta & 10.0 & 0.8 & 0.7 & 0.8 & 6.0 & 84 & 3. \\
\hline Industria manufacturera & 23.2 & 2.8 & 26.8 & 25.9 & 7.3 & 4.5 & 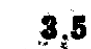 \\
\hline cowitruccton & 4.5 & 4.8 & 3.9 & 4.1 & 7.1 & -3.0 & \\
\hline Sulbotal bienes & 40.8 & $\mathrm{Cal}$ & 50.2 & 49.8 & 5.6 & 8.8 & as. \\
\hline Entricidad, gas y agua & 1.2 & 2.4 & 1.5 & 1.5 & 8.1 & 6.8 & 45 \\
\hline Insporte y comunicaciones & 7.2 & 206 & 10.1 & 10.3 & 13.9 & 2.2 & 10 \\
\hline Semotal servicios básicos & 8.4 & 100 & 11.6 & 11.8 & 13.1 & 2.7 & \\
\hline Counercto y finanzas & 17.8 & $10: 3$ & 17.4 & 17.6 & 3.5 & 6.1 & \\
\hline Cuvilerno & 5.5 & 10 & 4.8 & 4.7 & 2.8 & 2.8 & 25 \\
\hline Survicios diversos & 18.5 & 107 & 16.0 & 16.0 & 3.4 & 2.4 & $\operatorname{ras}$ \\
\hline Sulatal otros servicios & 41.8 & $\operatorname{mas}$ & 38.2 & 38.3 & 3.4 & 4.1 & \\
\hline Funlucto total & 100.0 & 120 & 100.0 & 100.0 & $\mathbf{5 . 0}$ & 4.0 & 90 \\
\hline
\end{tabular}

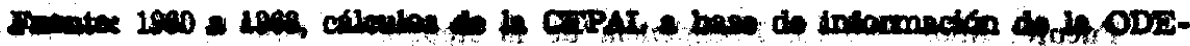
PLAN; 1969, estimaciones de la $G_{\text {num }}$; of

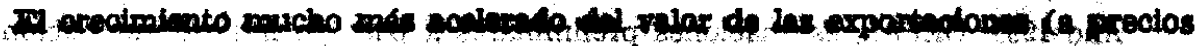

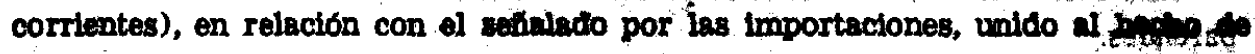

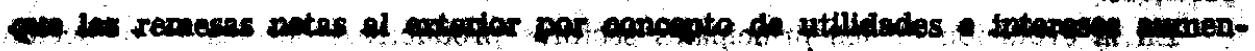

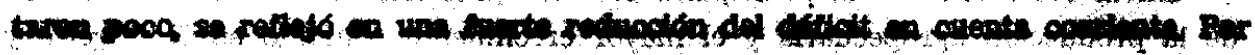


Dtre parta a pesar de que las entradas netas de cespitales autbriomos theran intertores a bas de 1968, ol superánit del batance de pagos fae to 112 millonos te chlares, es decir abranzó un nivel similar al ded año precedente.

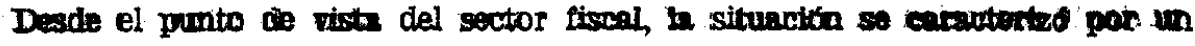

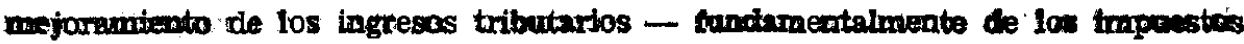
intirectos - y un aurnento de los gastos a un rituno mucho mones ripido que el de los ingresos; como consecuencia se protujo un axmento del horro corrtente I una rectuoción dei deficit fiscales.

Por sitimo, cabe sefílar el muevo incremento que alcancaron los procios it

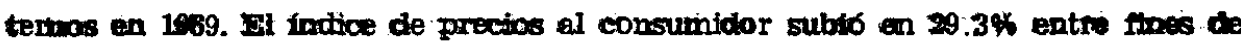

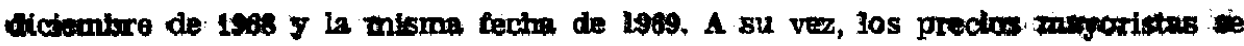

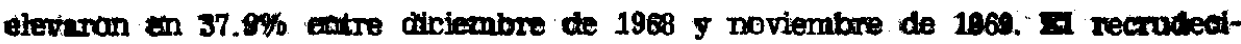
mitento en el atea as ins precios, en especial el ocurrido en los priminos mens

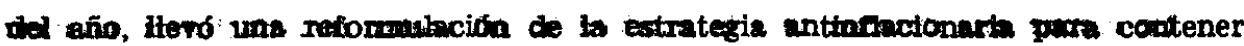

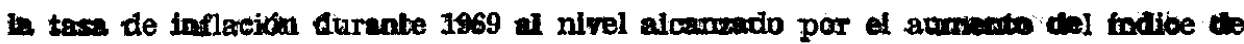

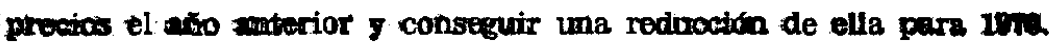

2,-Comportamiento de los principales sectores de la producción.

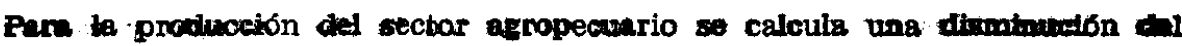
anden $3,4 \%$. Iote decrecimiento fue motirado exchasivenente por la prowne-

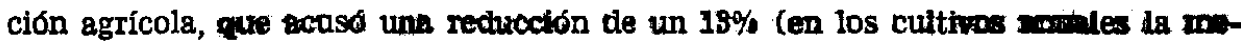

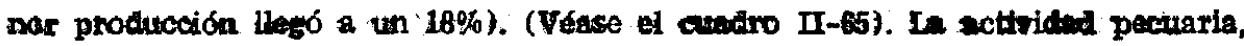

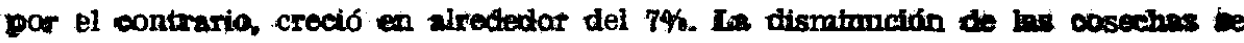

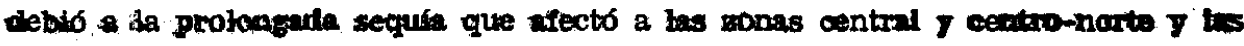
fwertes thelades de fin del año 1968.

CUADBO II-65

CHIIE: INDICES DE PRODUCCION AGRICOLA, 1967 A 1969

$$
(1968=100)
$$

\begin{tabular}{lrrr}
\hline & 1967 & 1968 & 1968 \\
\cline { 2 - 4 } T o t a 1 & 98.2 & 100.0 & 81.7 \\
Cerealum & 96.8 & 100.0 & 81.3 \\
Leguminosas & 133.4 & 100.0 & 73.1 \\
Papas & 98.7 & 100.0 & 83.1 \\
Cumivos industriaios & 97.7 & 100.0 & 96.7 \\
Vinos & 91.6 & 100.0 & 77.0 \\
\hline
\end{tabular}

Fuente: Cepal a base de informaciones de: Otidan de Punifictiolion Agrivith

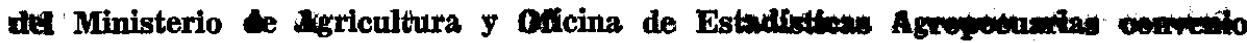

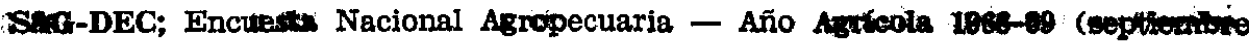
19997. 
- La baja en los cereales alcang 6 a $187 \%$, con disminuoioned te to arequ

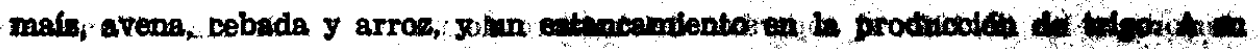

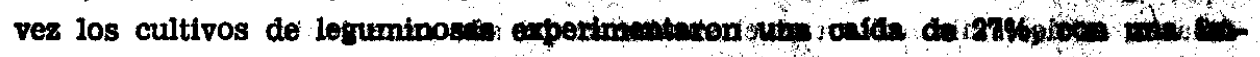

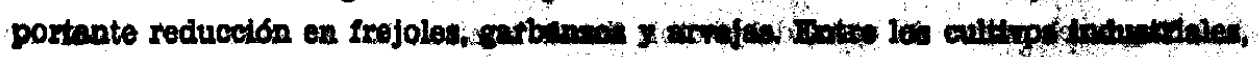

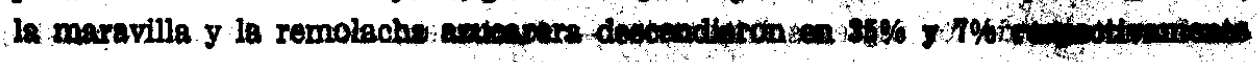

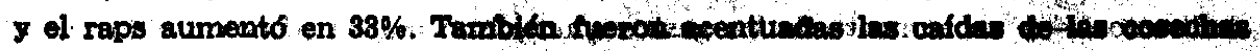

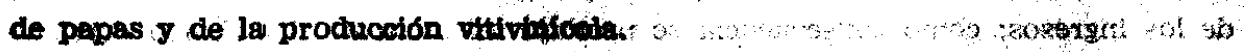

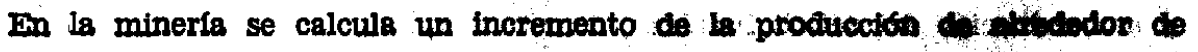

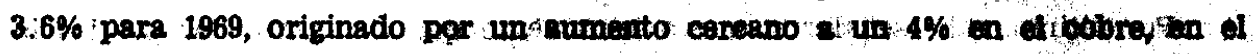

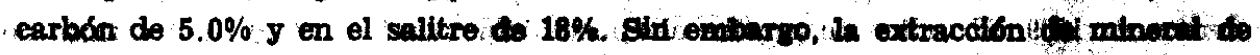

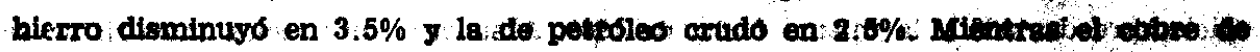

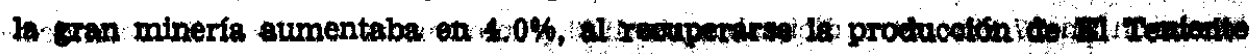

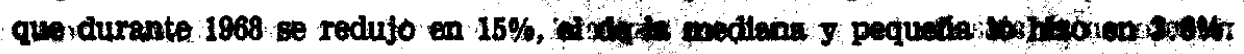

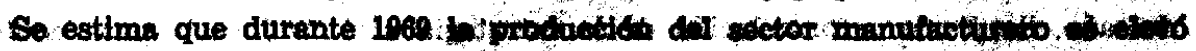

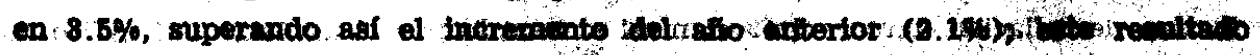

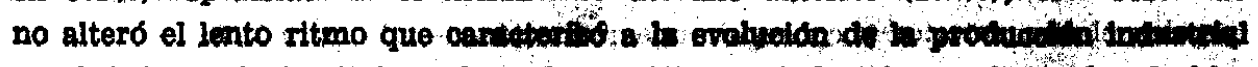
en el ultimo trienio. (Véase el cundro II-66) Las industrlas tradiofog las de bienes de consumo personal crecioron mus lontamente, ta major prodicholon to ra-

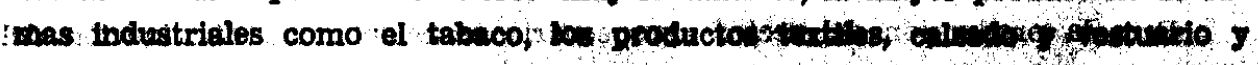

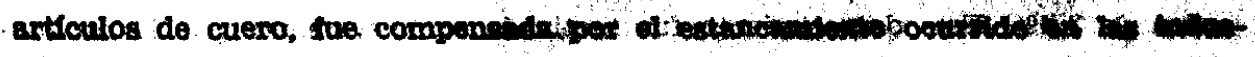

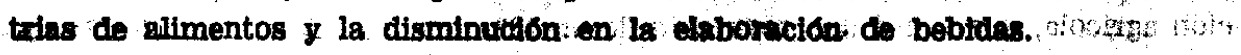

La caida en is actividad agricola din thids influys on el menoxiniva do pro-

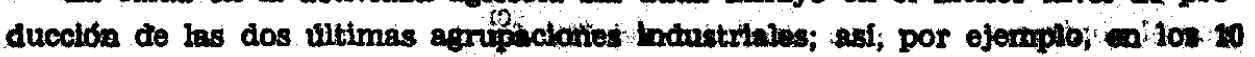

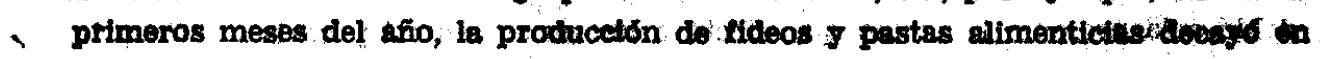
algo mís de $6 \%$, la de azicar en más de $4 \%$ y ta te cerveza, sobre a $8 \%$ w two de industrias productoras de materias primas y blenes intermedios aumento su producción en más de 7\%, a causia da 1 \%or ainamismo de las inđustrias de productos químicos, de derivados del carbón y petróleo, metálicas básicas y minerales no metálicos (sobre todo el cemento), por ultimo, las industrias del grupo metalmecánico, mostraron un crecimiento algo superior al $6 \%$, que se explica fundamentalmente por el aumento en la producción de material de transporte.

$$
\text { CUADRO II-66 }
$$

CHILE: INDICE DE PRODUCCION MANUFACTURERA, 1967 A 100.;

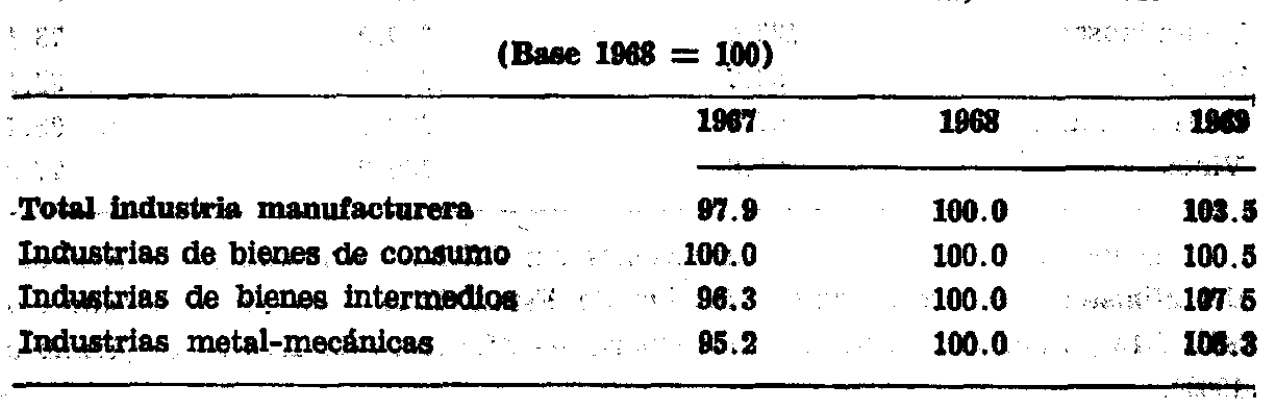

10 
Fuentes: Cẹpal a base de estadísticas de: CORFQ, División de Planificación Industrial - Datos Básicos Sector Industrial Manufacturero periodo 1960-67. Dirección de Estadística y Censos - Indice de Producción Industrial Manufacturera. Sociedad de Fomento Fabril, información directa.

El sector de la construcción tuvo una recuperación en 1969 y se estima que crecio en 6\%; ello se debio sobre todo a la reactivación de las obras públicas, que según cálculos de los gastos efectuados en los ocho primeros meses del año, se incrementaron en alrededor de $8 \%$ en valores reales. A su vez, la edificación total aumentó en alrededor de $4 \%$. Si bien la superficie de edificación iniciada por el sector públlico muestra una contracción de 30\% entre los ocho primeros meses de 1969 y el mismo lapso de 1968, la súperficie proyectada por el sector privado en un lapso similar aumentó en $27 \%$, to cual más que compensa la reducción anotada.

La evolución del volumen de bienes producidas y de las mayores importaciones, influyó en el crecimiento logrado por servicios como transporte y comercio, que aumentaron en $5.0 \%$ y $4.3 \%$ respectivamente. Entretanto la generación de energía eléctrica aumentó en $4.5 \%$.

\section{3) Oferța y demanda globales.}

En 1969, la cantidad total de bienes y servicios disponibles en la economía superó en alrédedor de $4 \%$ è nivè alcánzado el año enterior. (véase el cuadro II-1967). De igual manera que en 1968, el crecimiento de cerca del $10 \%$ de las importaciones totales fue fundamental en el comportamiento de la oferta global.

Del lado de la demanda, crecio acentuadamente el volumen de las exportaciones, en alrededor dèl $6 \%$ la inversión total y en $3 \%$ el consumo. El gasto en maquinarias y equipos, elemento dinámico en 1968, registró una tasa más baja en 1969, pof efecto del menor aumento de las importaciones de bienes de capital. Al revés de lo sucedido el año anterior, el gasto en edificación y especialmente en obras públicas mejoró en $6 \%$. De otro lado, el aumento de las inversiones públicas en 1969 -que totalizaron alrededor del $60 \%$ de la inversión total- se estima en $11 \%$, con un mayor crecimiento en urbanizacion y comunicaciones, como resultado de los programas de la Empresa Nacional de Telecomunicaciones, del plan de expansiones en el servicio de agua potable de la capital y las mayores obras del Ministerio de Obras Públicas; también fụeron importantes los aumentos en transportes y ciertos renglones industriales (a través de Industria Azucarera Nacional, S. A., Corporación de Fomento de la Producción y Petroquímica Chilena). Por su parte las inversiones en los sectores de vivienda y minería mantuvieron los niveles del año anterior. (Vẹase el gráfico II-9.).

El consumo total se expandió en $3,0 \%$, con una aumento algo superior en los gastos de consumo gubernamentales. El menor crecimiento del consumo público en relación con 1968 corresponde en ciertos aspectos al comportamiento de los gastos fiscales. Según estimaciones del Miniłterio de Hacienda, mientras los ingresos corrientes aumentaron en $10 \%$ en valores reales, con una creciente 


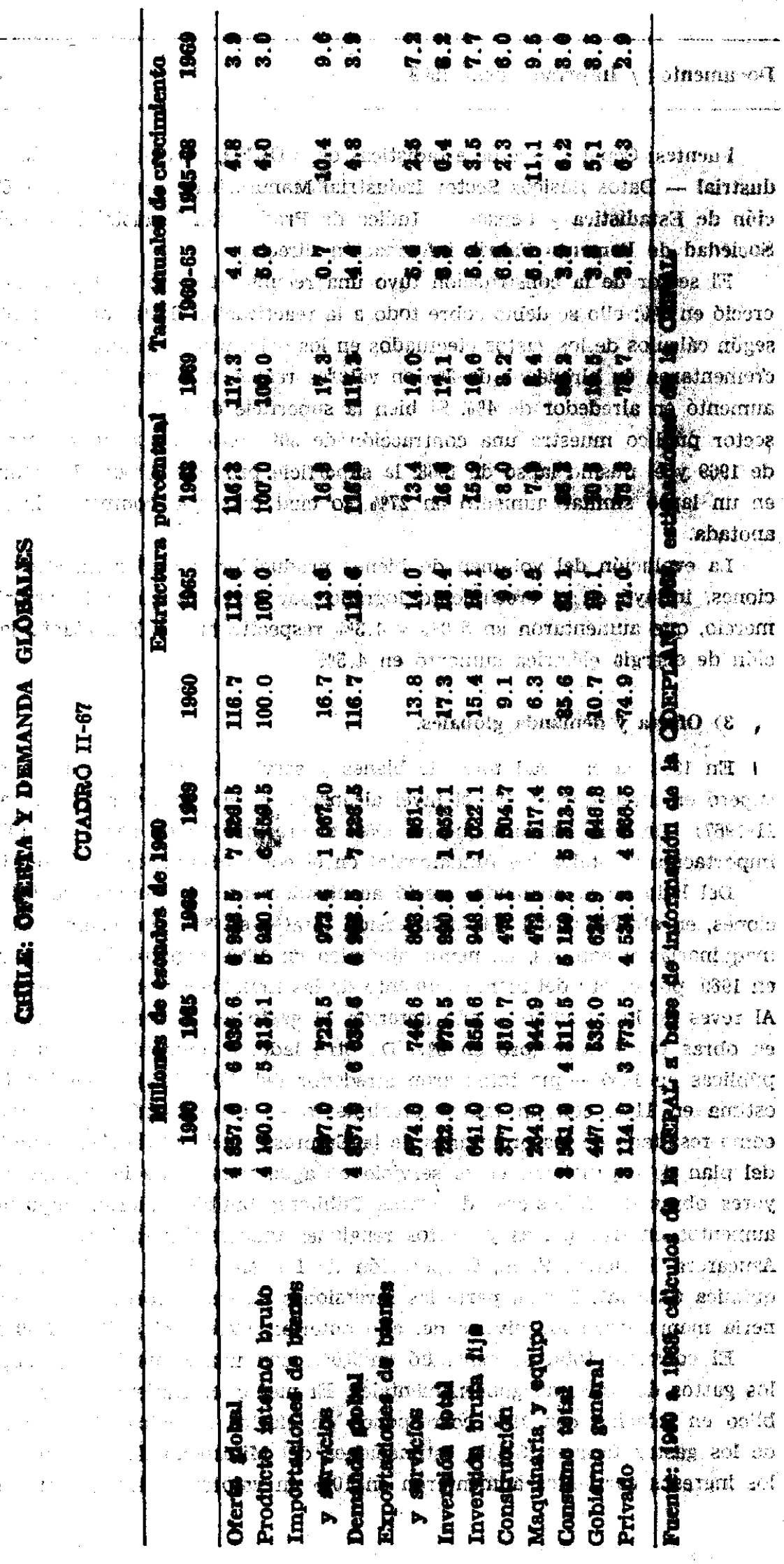


a) EVOLUCION DEL PRODUCTO BRUTO INTERNO Y DE IAS INVERSIONES (Millones de escudos de 1960)

Escala semilogaritmica

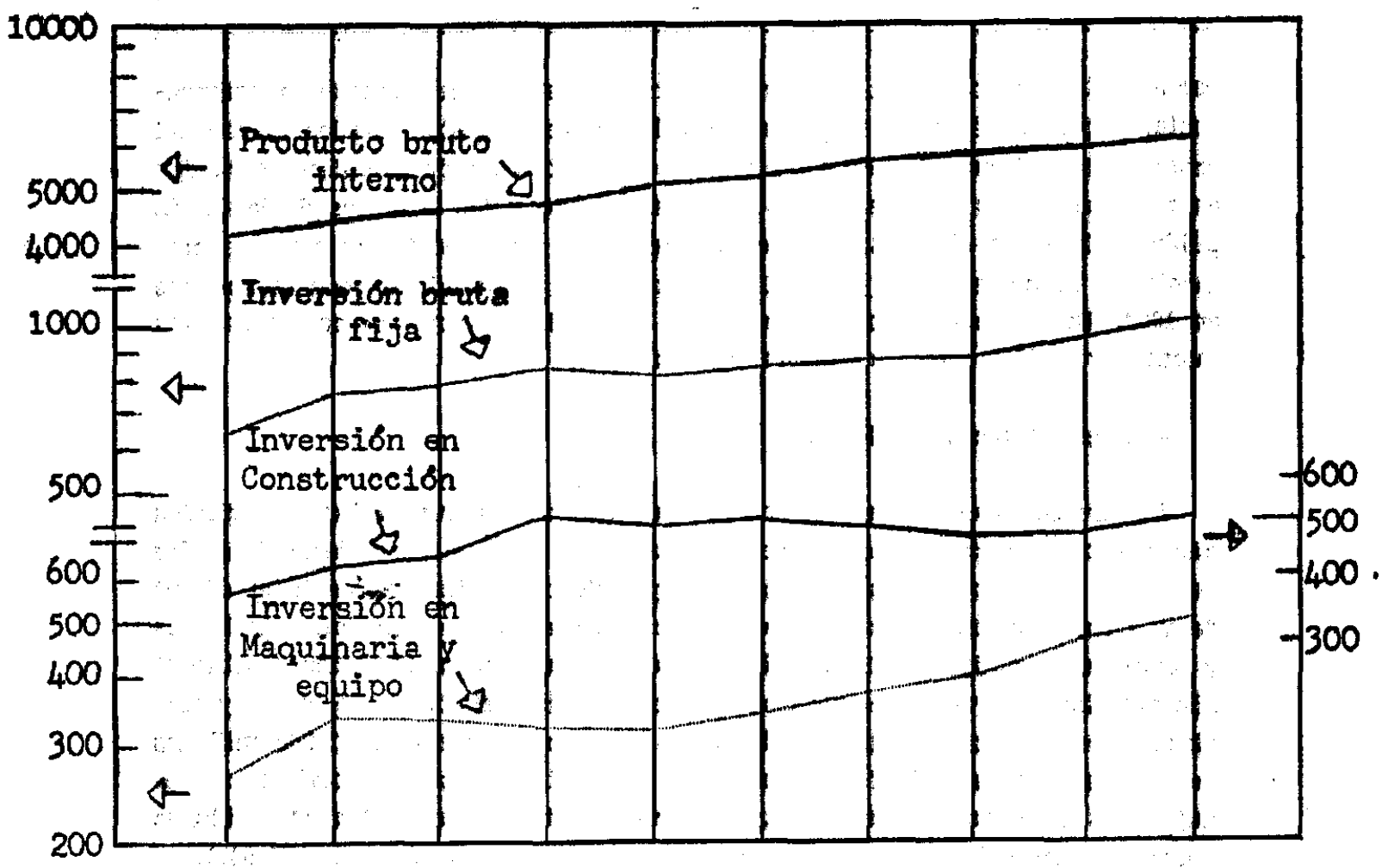

b) TENDENCIAS DEL SEGTOR EXTERNO

(Millones de dólares do 1960)

Escala natural

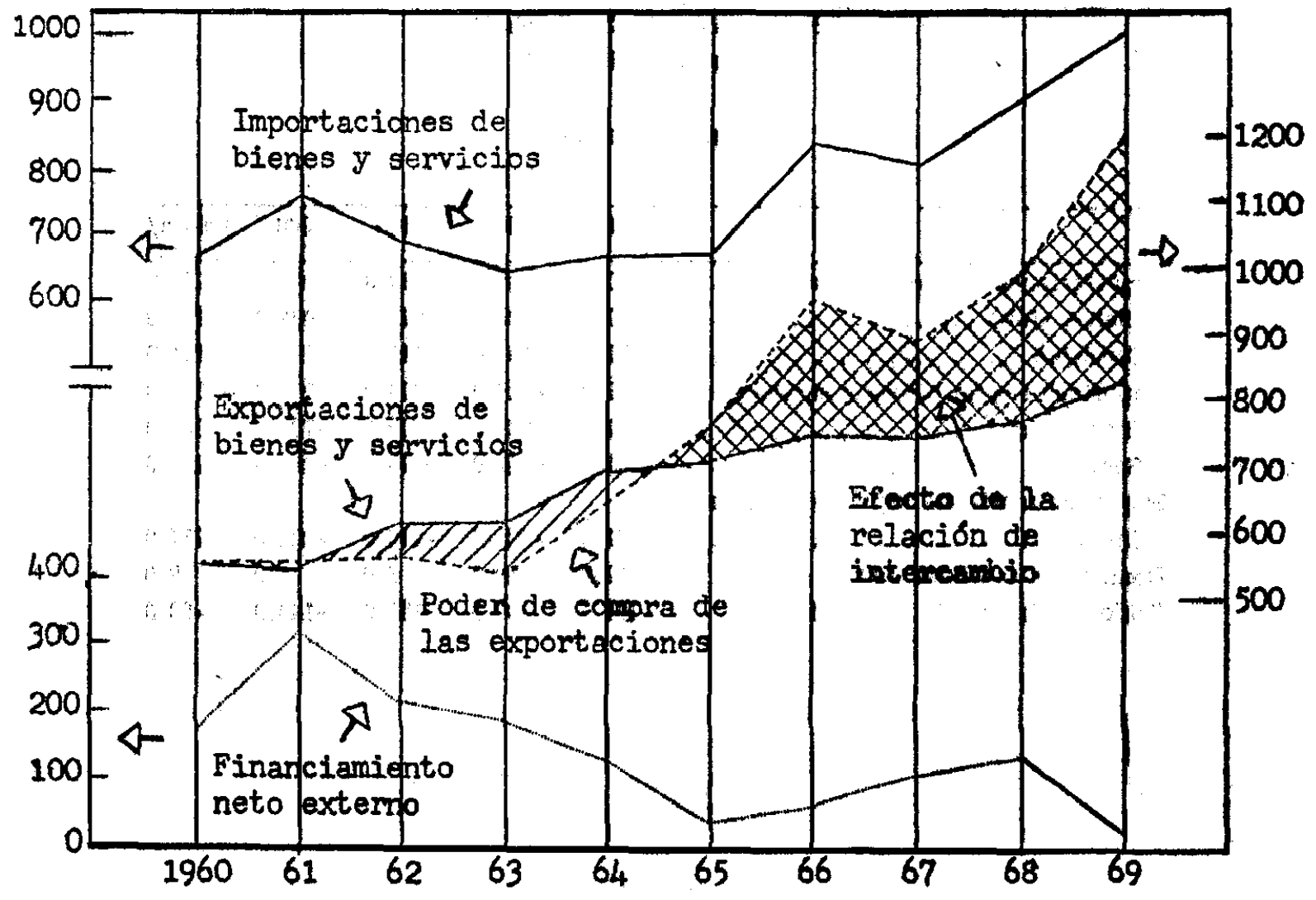




\begin{tabular}{|c|c|}
\hline & 6.160\%, \\
\hline Whones: & 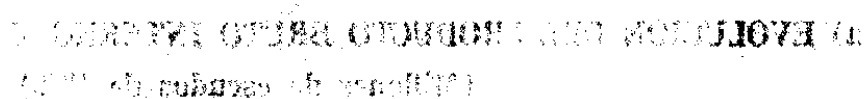 \\
\hline
\end{tabular}

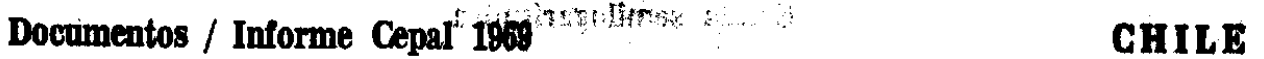

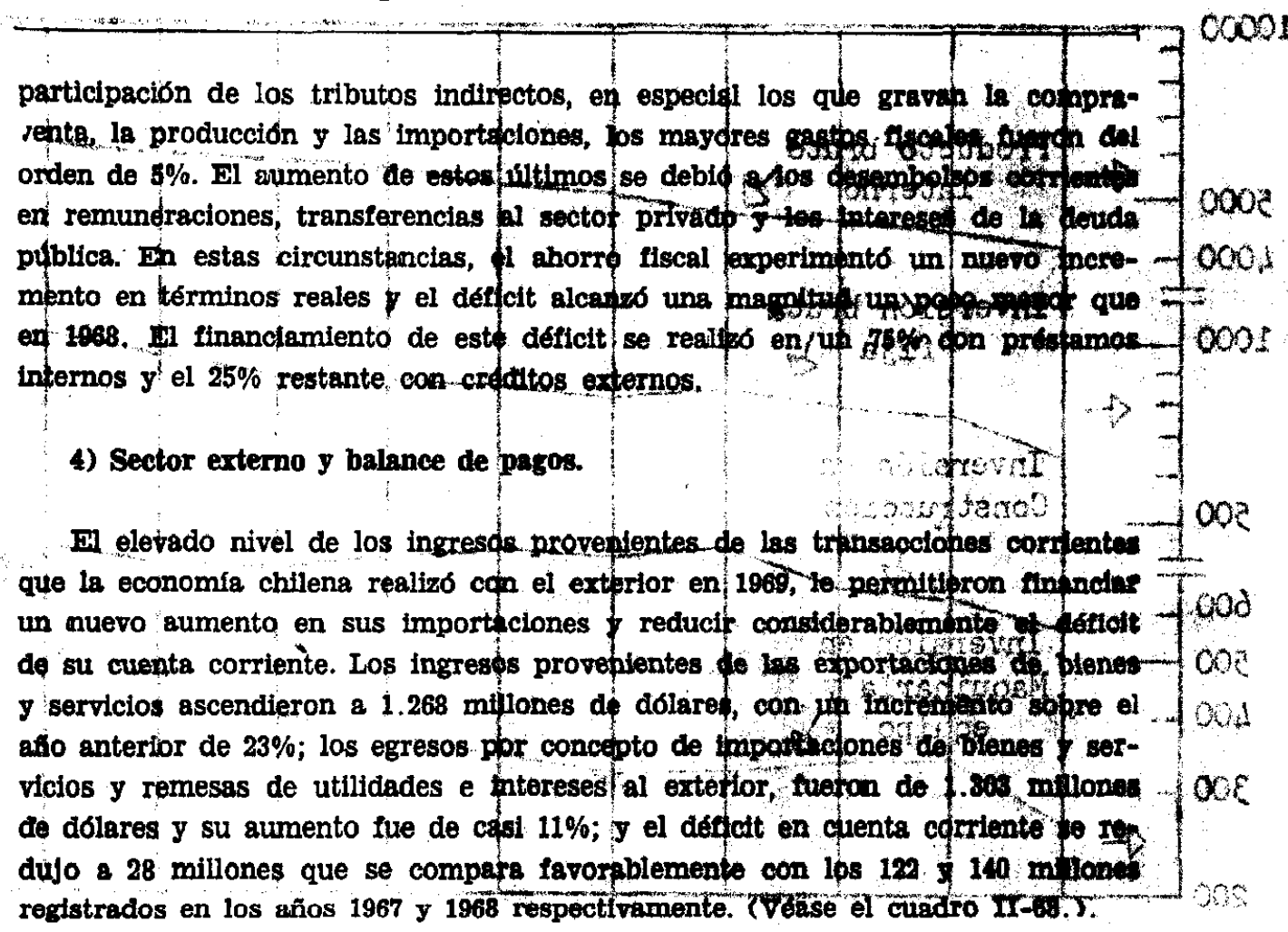

participación de los tributos indirectos, en especial los que gravah la colapra-

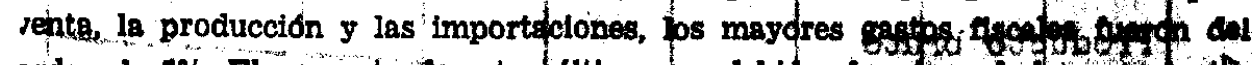

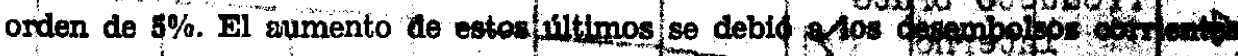

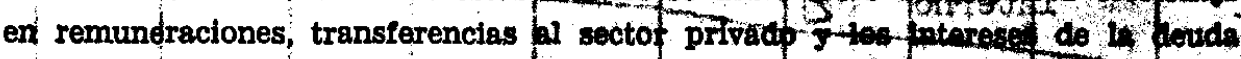
pública. En estas circunstancias, \& ahorr fiscal axperimpinto un nuevo pere-

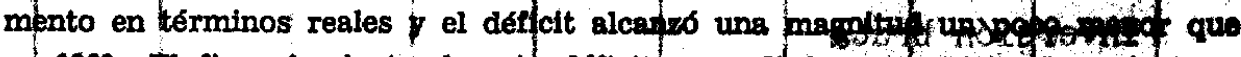

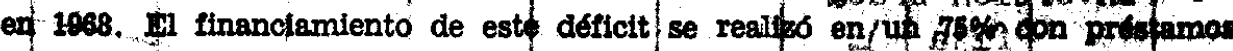
internos $y$ ? el $25 \%$ restante con credutos externos.

4) Sector externo y balance de pagos.

FI elevado nivel de los ingresqa provententes de las transagctohes corrienten

que la economia chilena realizo con el exterior en 1969, to permitusron fininolas

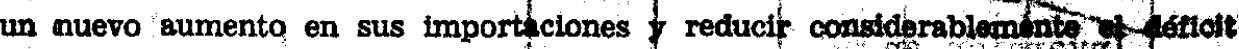
de su cuenta corriente. Los ingreses provepientes do las exportactgies of blenes

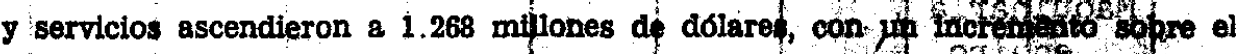
afio anterior de $23 \%$; los egresos por concepto de tmpartalones do biones f servicios y remesas de utilidades e ntereses/al extefior, tueton de 1.803 millones de dolares y su aumento fue de cosis $11 \%$; y el détit en cuenta corriente to re. regtstrados en los años 1967 y 1968 respectivamente. (V'áse el cuadro Ir-6o.s.
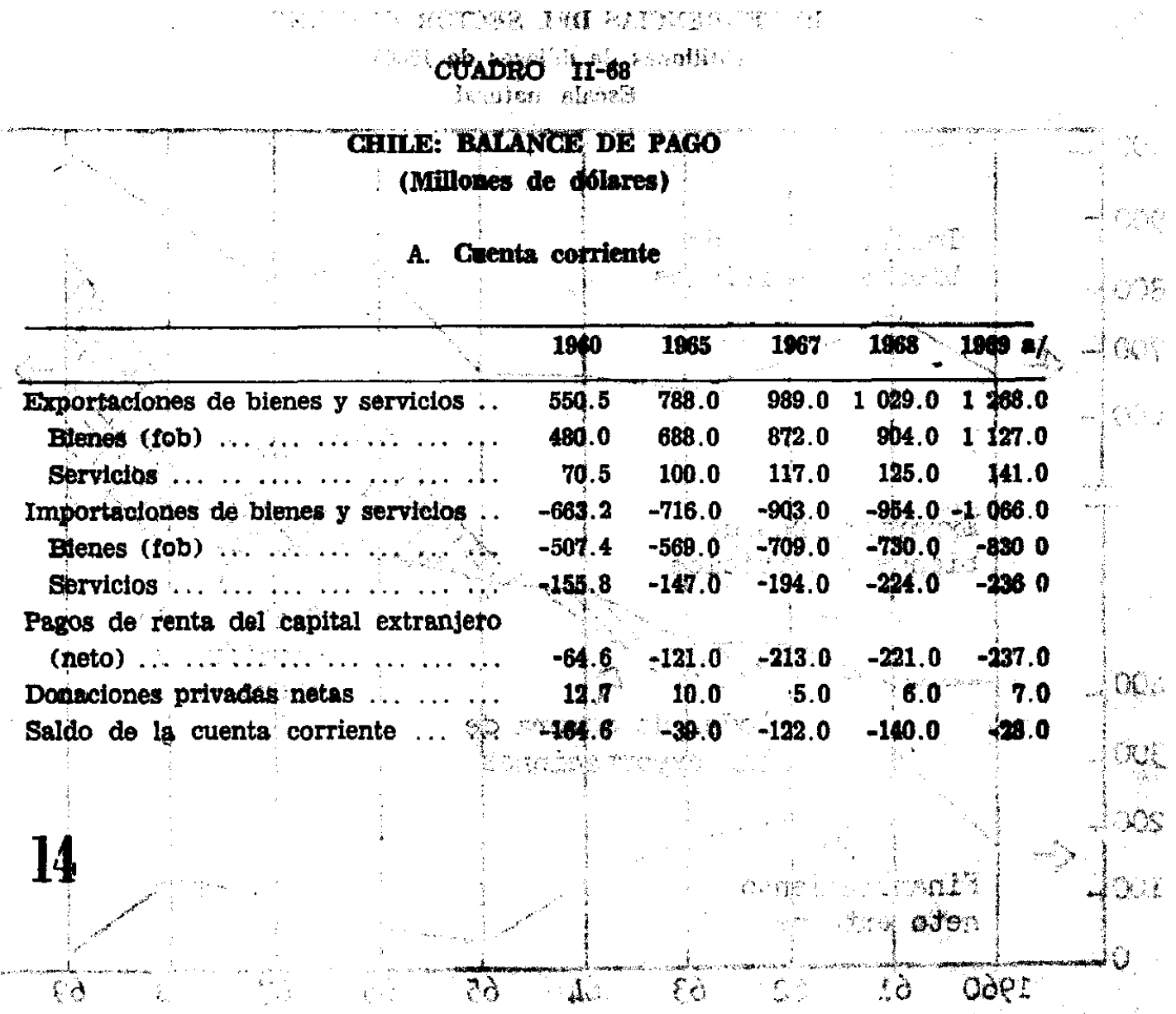


\begin{tabular}{|c|c|c|c|c|c|}
\hline & 1960 & 1965 & 1967 & 1968 & 1969 a) \\
\hline B. Cuent & de cal & ital & & & \\
\hline \multicolumn{6}{|c|}{ Financiamiento neto externo $(a+b+c$} \\
\hline 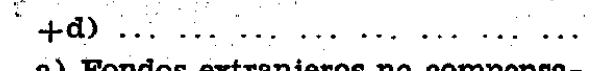 & 164.6 & 39.0 & 122.0 & 140.0 & 28.0 \\
\hline $\begin{array}{l}\text { a) Fondos extranjeros no compensa- } \\
\text { torios } \ldots \ldots \ldots \ldots \ldots \ldots \\
\ldots\end{array}$ & 82.6 & 80.0 & 158.0 & 292.0 & 182.0 \\
\hline 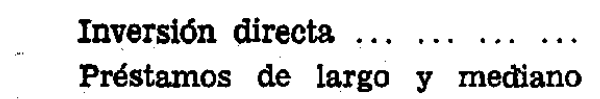 & 29.0 & -38.0 & 19.0 & -54.0 & -6.0 \\
\hline plazo $\ldots \ldots \ldots \ldots$ & 50.5 & 183.0 & 216.0 & 445.0 & 344.0 \\
\hline Amortizaciones $\ldots \ldots \ldots \ldots$ & -41.4 & -90.0 & -105.0 & -145.0 & -159.0 \\
\hline Pasivos de corto plazo ... ... & 10.2 & 26.0 & 23.0 & 45.0 & $\cdots$ \\
\hline Donaciones oficiales $\ldots \ldots \ldots$ & 34.4 & -1.0 & 5.0 & 1.0 & 3.0 \\
\hline $\begin{array}{l}\text { b) Fondos } 0 \text { activos nacionales no } \\
\text { compensatorios } \ldots \ldots \ldots \ldots \ldots\end{array}$ & -8.7 & -36.0 & & -2.0 & \\
\hline c) Errores $y$ omisiones $\ldots \ldots \ldots$ & 45.6 & 34.0 & -70.0 & -35.0 & -42.0 \\
\hline d) Financiamiento compensatorio & & & & & \\
\hline (-aumento) $\ldots \ldots \ldots \ldots \ldots$ & 45.1 & -39.0 & $3 \pi .0$ & -115.0 & -112.0 \\
\hline $\begin{array}{l}\text { Préstamos de balance de pagos, } \\
\text { atrasos comerciales, pagos di- } \\
\text { feridos, posición con el FMI y } \\
\text { otros pasivos de las autorida- } \\
\text { des monetarias ... . . . . . . . . }\end{array}$ & 59.9 & 133.0 & 45.0 & 61.0 & 46.0 \\
\hline Amortizaciones $\ldots \ldots \ldots \ldots \ldots$ & -31.4 & -123.0 & -55.0 & -87.0 & -72.0 \\
\hline Oro y divisas (-aumento) ....... & 16.6 & -49.0 & 44.0 & -89.0 & -860 \\
\hline
\end{tabular}

Fuente: Fondo Monetario Internacional, Balance of Payments Yearbook, vol. 17 y 20. a) Estimaciones del Banco Central.

E1 valor de las exportaciones de blenes se elevó a 1127 millones de dolares. y superó en $25 \%$ el nivel de 1968 . Esta expansión se debió sobre todo al aumento de las ventas de cobre, tanto de las grandes empresas como de la mediana y pequeña minería, cuyo valor subió en alrededor de $30 \%$. El alza del precio del metal es el factor fundamental que explica el mayor valor del total exportado, ya que el incremento en el volumen fue sólo de 3.4\% (en 1968 se exportaron 637259 toneladas y en 1969, 659000 ). Durante 1969 el precio medio del cobre alcanzo a 64.8 centavos de dólar la libra, en comparación con 53.6 centavos en 1968.

El resto de los productos mineros mantuvo en promedio los niveles alcanzados en 1968. Las cifras de los diez primeros meses de 1969 indican que los mayores embarques de salitre y yodo fueron compensados por las disminuciones ocurridas en el mineral de hierro y el molibdeno. 
Las exportaciones industriales, con un valor cercano a los 100 fallones do

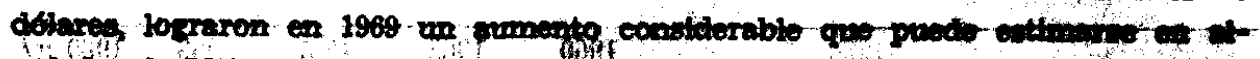

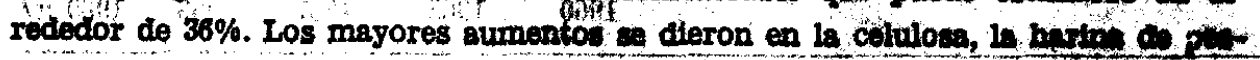

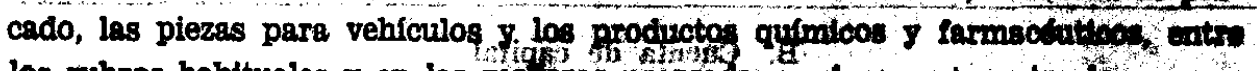

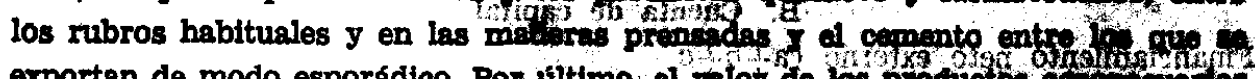

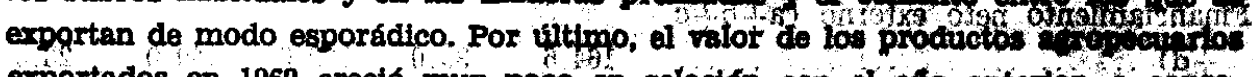
exportados en 1969 crecio muy poco en relación con ol afo antertos of oper

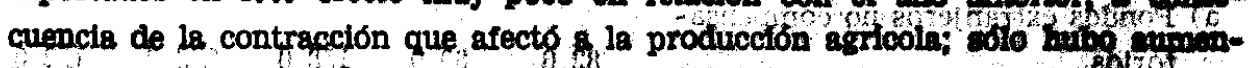
tos importantes en inadera y lana.

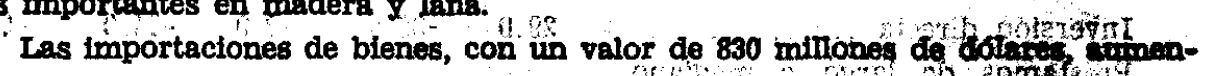
taron en cerca de $14 \%$, tasa muy superior al $3 \%$ registrado en 196. ras foromento correspondio en su mayor parte a las importaciones de mates of

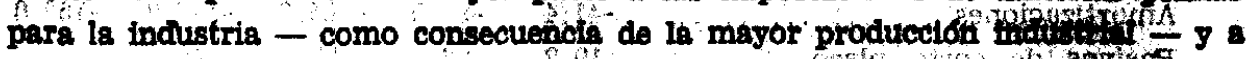

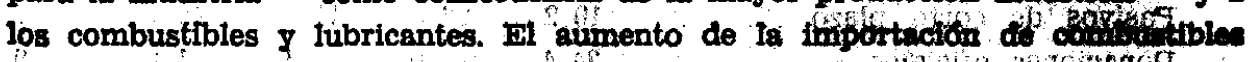
So debló a la reducción suitrida por ti produccion nactotial.

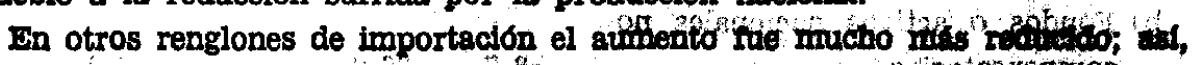

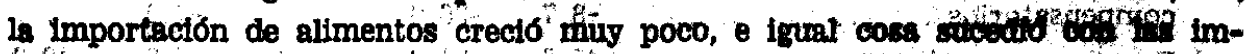

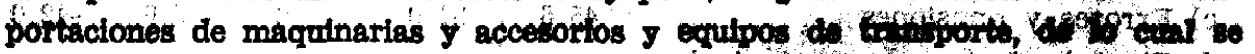

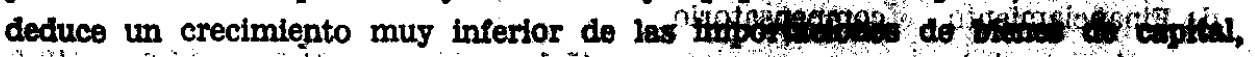

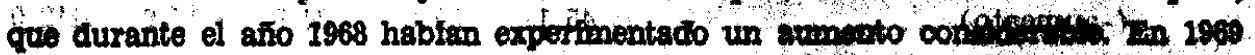

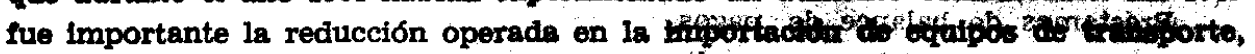

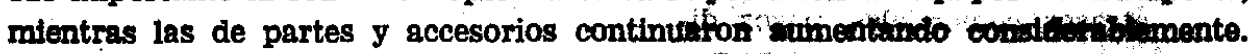

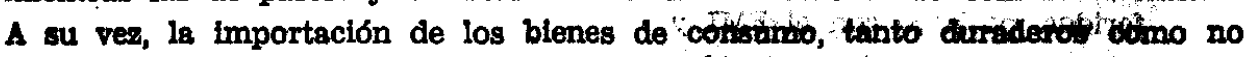
duraderos, se mantuvo prácticamente estanchicing

Fi reducido saldo negativo en th cuents corriente de 1969 , ogregado a un intreso neto de capitales autónomos dimque de un nivel algo menor al as 1968 ,

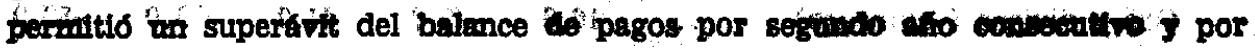
uin manto de 112 millones de dolares.

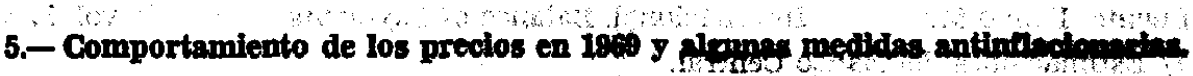

In 1999 se repistra uns aueve acelertegion del rituno de crecimiento do los precios internos. Il indice de precios al gopoumidor experimento un aupropto de

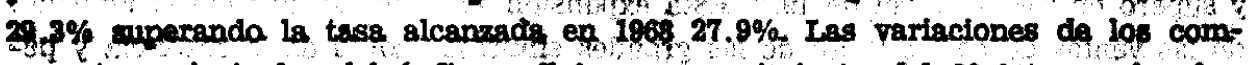
ponentes principales del fndice refelan un crecimiento del $28.0 \%$ en of noro

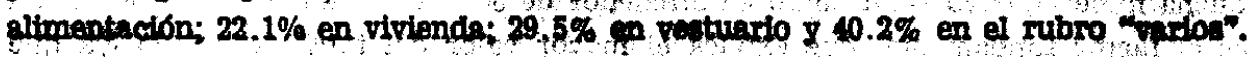

14 fadice de preclos al por mayor registro hasta novlembre de 1009 un crpiniento de $37.9 \%$, superando en poco mp de 5 puntos al abservado pox oto Indice en el mismo periodo en 1968 , In estos once meses, el componente de fos precios de productos nacionales chacto en $38 \%$, debido fundamentalmente al alra de los precios agropecuarios, que eumontapen durante el mismo lapse en $48.9 \%$. Ios precios mineros e Industriales subleron hasta noylembre de 1969 a pno the

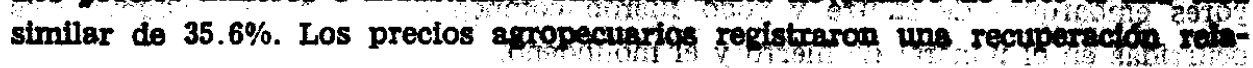


tiva trente al nivel general de precios al por mayor, despues del teterioro srido en los afios 1967 y 1968. Por ultimo, los preclos de los prodictos impoftados se elevaron en $38.2 \%$, variación símtlar a la de los productós nactónales to cual indica un alza algo inferior a la de igual periodo en 1968.

El rápido aumento de los preelos internos en los primeros meses del tho consejo tomar un confunto de medides en el orden nlscal, monetiorio y de th-

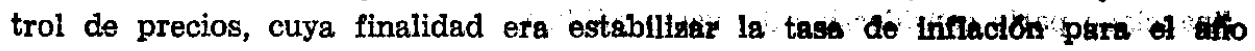
1969 al nivel alcanzado por el alza de los precios al consumidor en 1968 y hacer posible una cierta reducción en 1870. Las prinoipales medidas anunciadas en los primeros meses del segundo semestre fueron las siguientes:

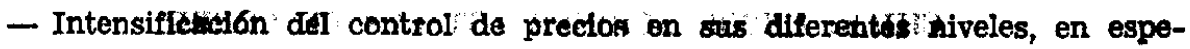
cial de los correspondientes a los articulos de consumo popular, danđo mayores recursos y atribuctones al organismo contralor (DIRINCO).

- Continuación y ampliación de la politica de abastecimienta haciendo uso de contingentes de importación e inclusa de mayores importaciones, en aquellos productos escasos o de altos márgenes de comercialización.

- En la política monetaria, limitación de la expansión del dinero y del crédito, el que se oriento hacia los sectores más dinámicos.

- En el campo fiscal, acentuación de la restrictión de los igastos corrientem; cese del endeuidamiento con el Banco Central; y redueción del régimen de drambicks:

- En materia de salarios, limitación de los aumentos de remuneracioneren $100 \%$ del aumento del costo de la vida.

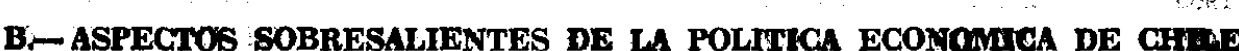

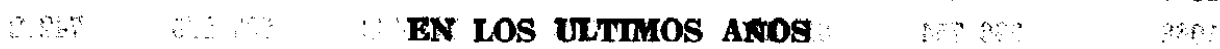 EN LOS ULTmOS ANos}

A pesar de las dificultades experimentadas por Chile en el teenie de-1060

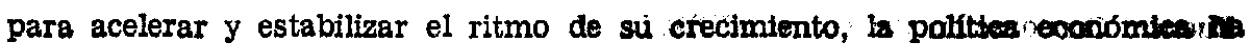
mostrado gran dinamismo en diversas áreas de importancia, lo que guramente influirá en su desarrollo en el próximo futuro.

Entre las iniciativas de mayor trascendencia sobresalen las dirigidas a modiffear las situaciones bésicas de la gran mineria del cobre y el stame de tenencia de la tlerra. En las secciones que siguen se ha tratado de reintr lassinTormaciones pertinentes sobre ambas materias a objeto de presentar un cuadro sumario de los propósitos y logros que sobresalen en esas expertonatas.

\section{1.-La politica del cobre.}

\section{a) Aspectos generales.}

Chile ha realizado en los dos ultimos decenios esfuerzos tendientes a conftgurar una politica del cobre que le permite una expansión de la producción. una mayor captación de los excedentes generados por la actividad minera y una ma- 


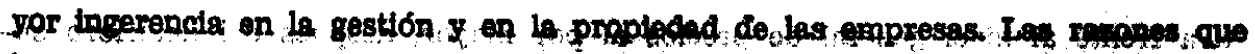

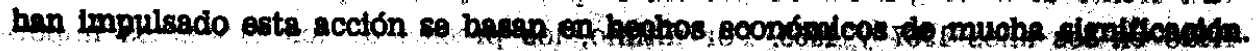

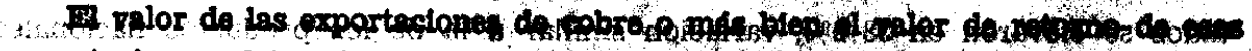

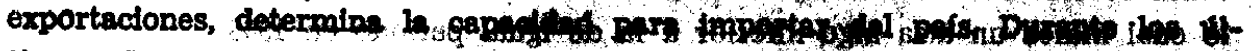

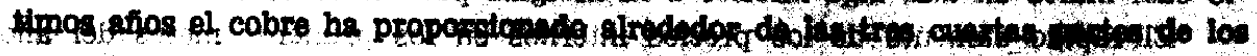

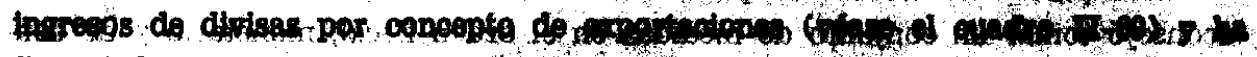

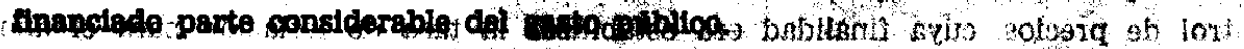

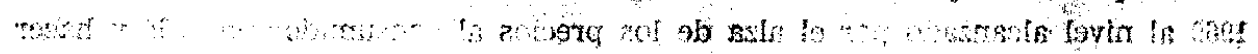

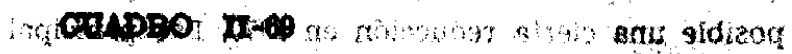

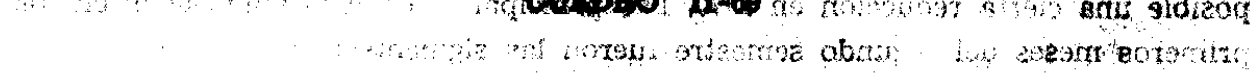

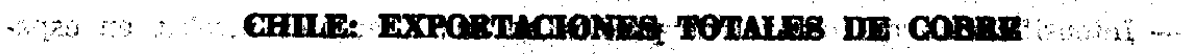

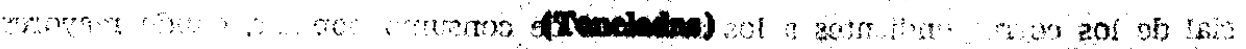

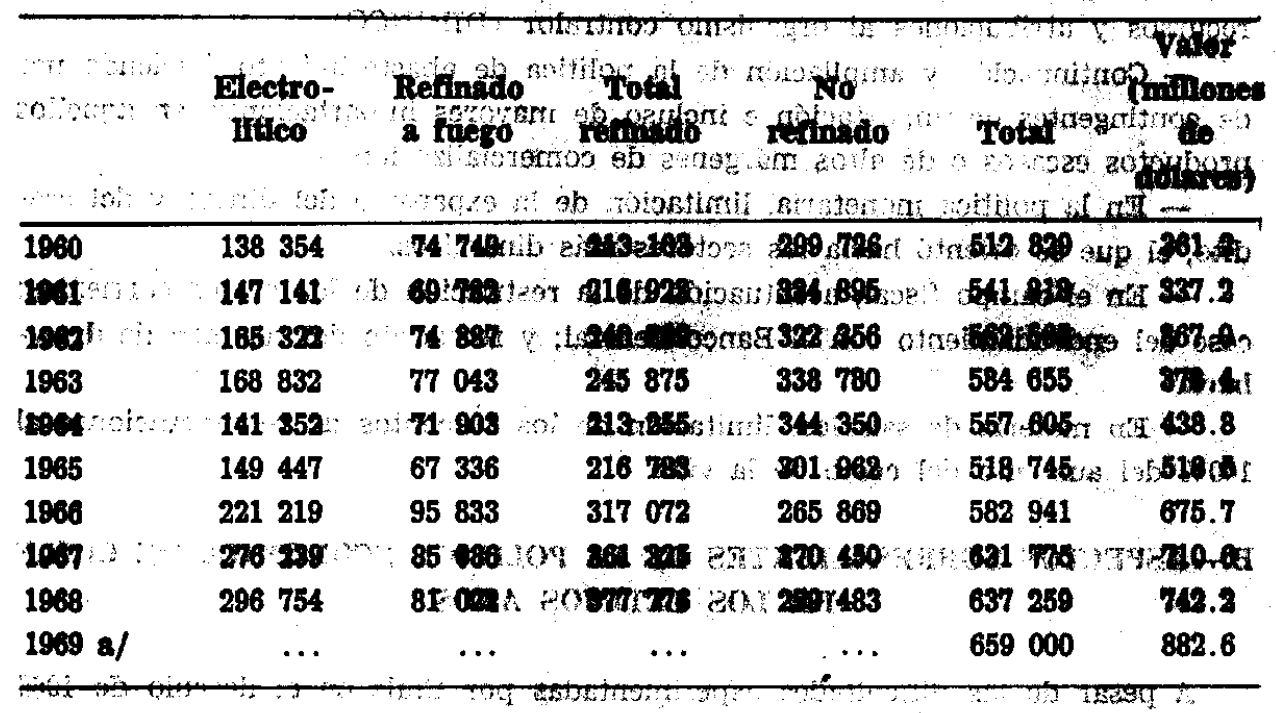

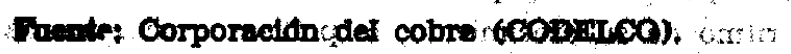

a) Estimación.

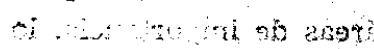

run oresert

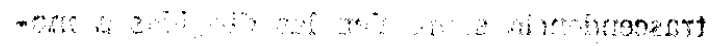

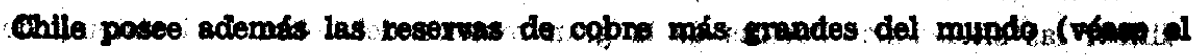

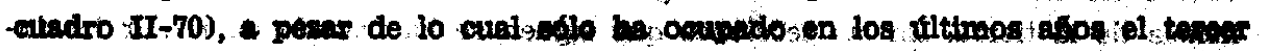

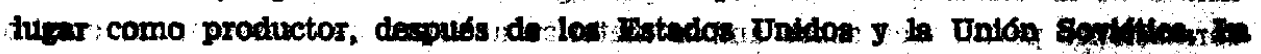

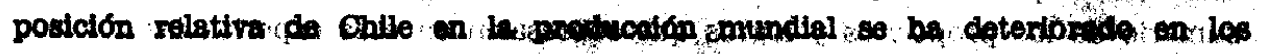
últimos afios. A fines del decento de 1940 Chtle contributa con el $17.2 \%$ de la producción mundial, proporcion que a fines de los anos sesenta mania bajacio a $13.6 \%$ y que en 1969 se estimaba en $12.7 \%$.

La tass de crecimiento de la producción chilens do cobre fup arappe $2.8 \%$ anual en el período 1960-69. La mayor parte de este crecimlento se debib a la pe-

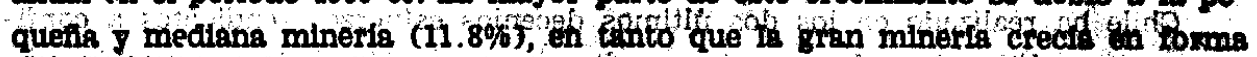

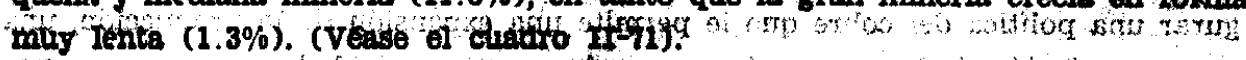
roc zotistome 
Con la promulgación de la Ley № 11828 , de 3 de mayo de 1955 , llamada la "Fey idel nuevo trato al cobre", se concretó el primer intento po fơrmutar ufía politica globil para esta importante actividad económica. La ley creó el Dephrtamento del Cobre, estableció un nuevo sisterna de tributación $42 \%$ aestinado a estlimular un programa de inversiones para aumentar la producctón; otorgo franquicias adiciớales a la producción de cobre electrolftico y concedito a las actí vidades de la grán minería del cobre el tho de cambio ofictali thás alto.

Los resultattís de la "ley del nuevo trato al cobre" no tueron los esperados, sobre todo en lo que toca a la obtención de niveles más altos de producción y mayores ingresos fiscales. Por ello se dictaron leyes posteriores que establecieron recargos tributarios a las empresas de la gran minería $43 /$.

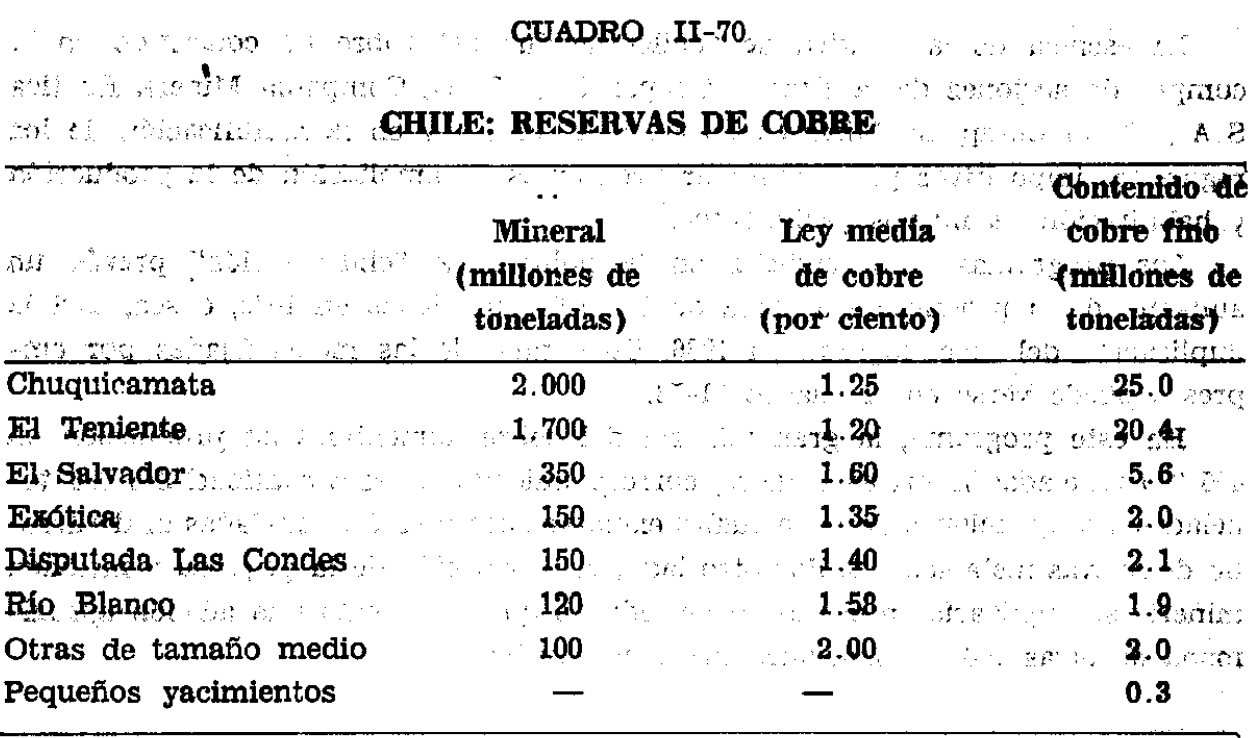

To t a 1

59.3

Fuente: Carlos Ruiz, Geología y yacimientos metalíferos de Chile, Instituto de Investigaciones Geologicas, Edtoriat Universttarta: Santtago de Chile, 1965.

A fines de 1964 el gobierno de Chite anunció una nueva política para el cobre a través de la suscripción de convenios con las empresas extranjeras que establecen: modificaciones en el rógimen tributario, asociación del Estado con las empresas y programas de producción. Esta política, conocida como "chilenización del oobre", fue ratificads por el Congreso en 1966.

427 Sestableció una tasa de $50 \%$ sobre las utilidades de las empresas dé la gran thinería y una sobretasa variable de $25 \%$ descendente en función de $110 \mathrm{~s}$ aumentos de producción que se lograron sobre la producción básica, calculada sobre el $95 \%$ del promedio registrado durante los años 1949-53. A las nuevas $5 \mathrm{~m}^{2}$ presas quio se crearan se les aplicaría sólo la tasa del $50 \%$.

48. Ley No 14.603, de 1961, que estableció un reaargo de $5 \%$ y Ley Ne 14.683 , de 1961 quie agregó otro de $8 \%$. 


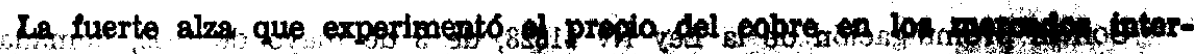

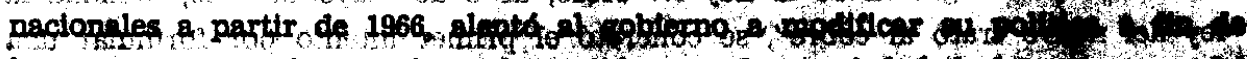

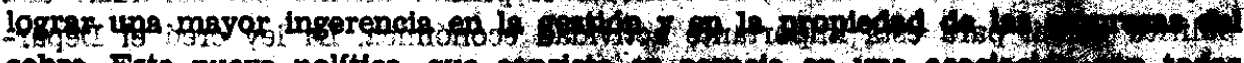

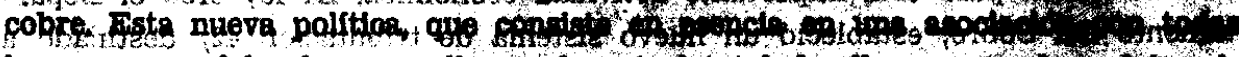

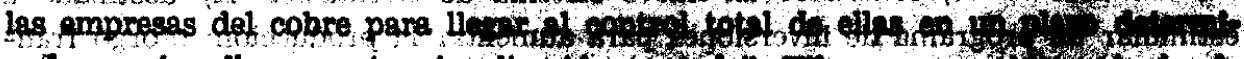

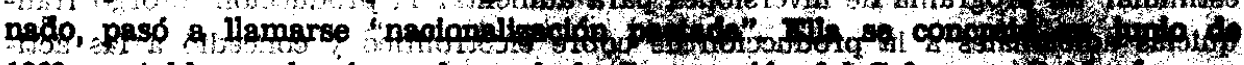

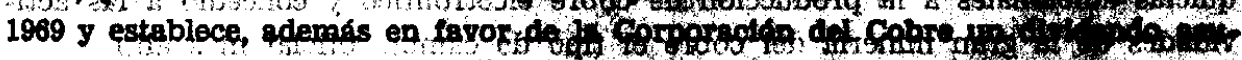

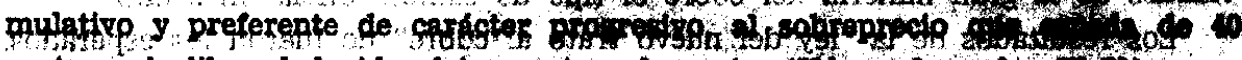

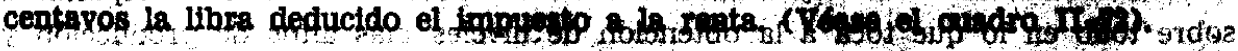

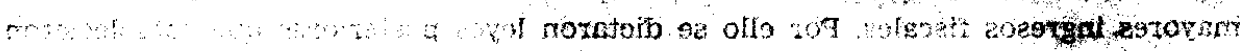

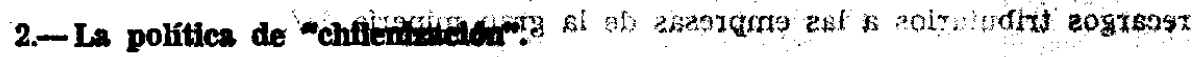

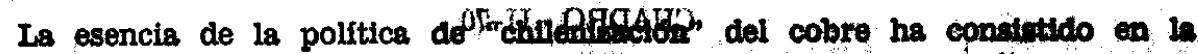
compra de acciones de la Braden Copper Co., (51\%), Cormpanfa iftura Inothes

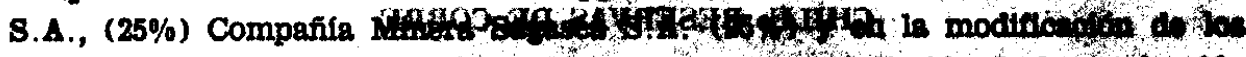

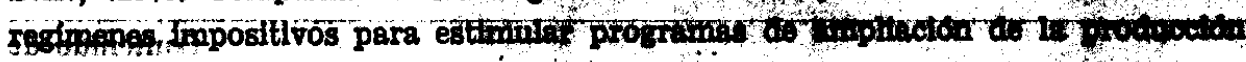

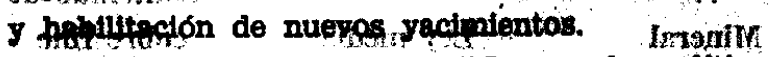

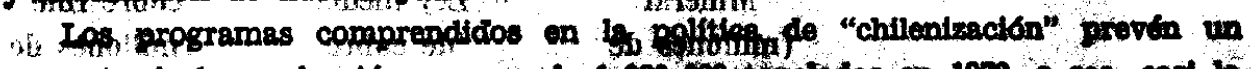

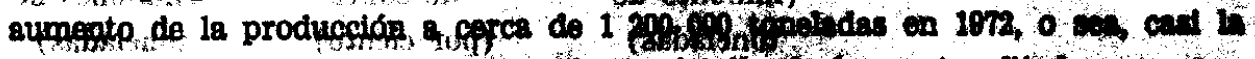

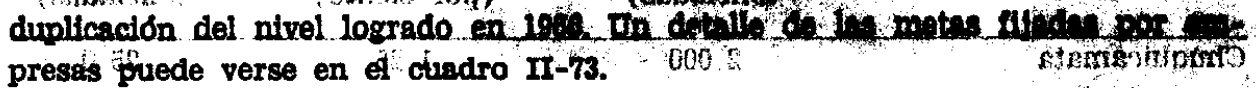
presas fuede verse en el chadro $I-73$.

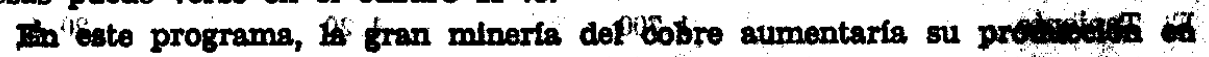

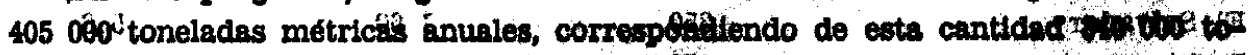

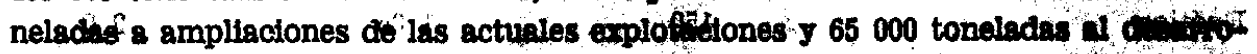
llo de tuevas instalaciones. Por otro lado, if producelón de to pequeat of eling

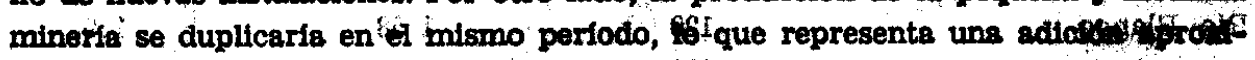
madá de otras 100000 tónéladas mótricas adfulales.

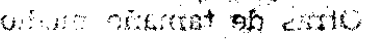
s.5

CUADRO II-71

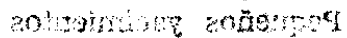

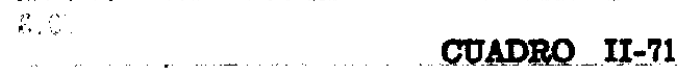

CHINE: PRODUCHOA DP COBRE PRHMARIO

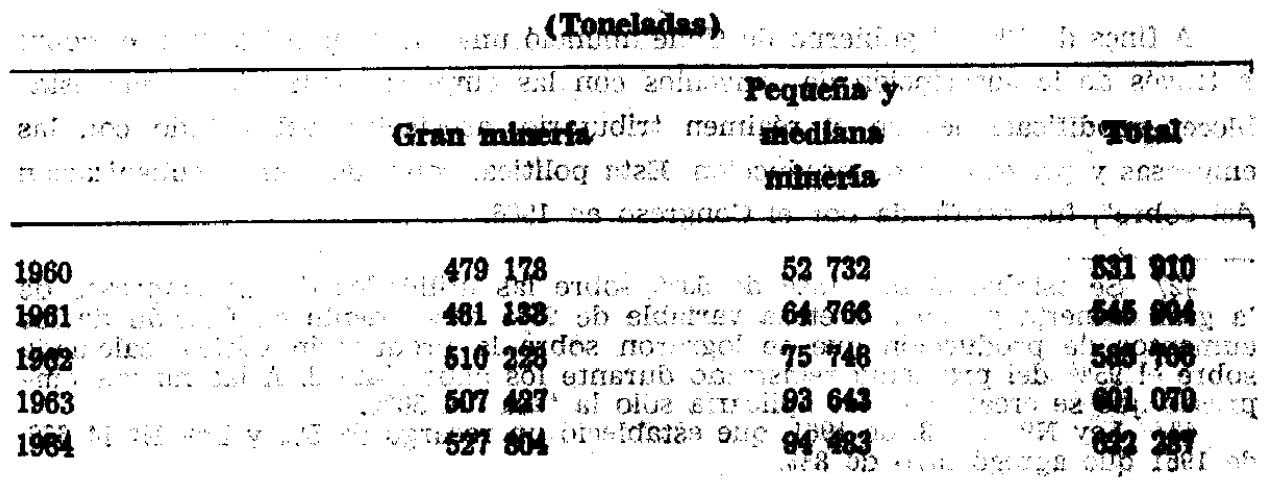


Dokumentos / Informe Cepal 1969

amrote

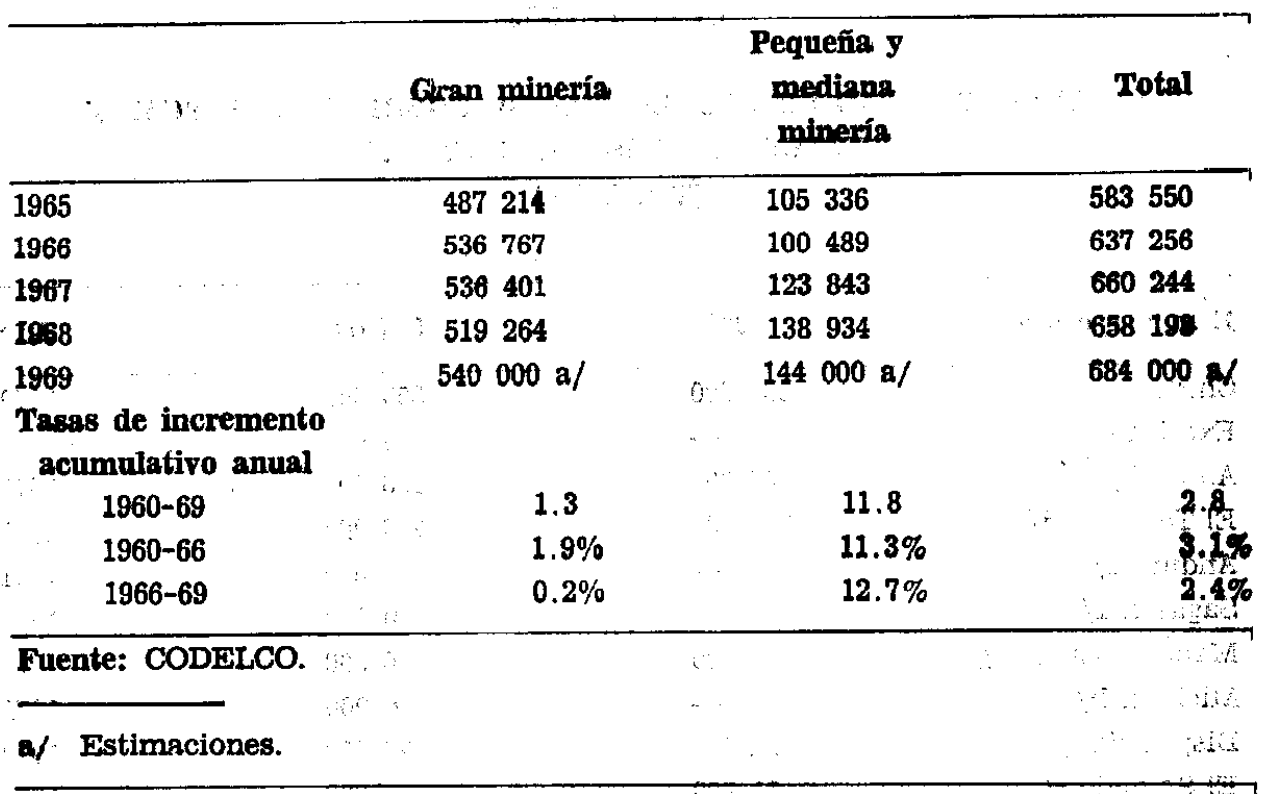

CUADRO II-72

CHILE: TABLA APLICABLE AL SOBREPREGIO DEL COBRE

Precio medio por

Ubra de cobre

de dólar por libra)

Porcentaje aplicable
a cada centavo de
variación

Porcentaje aplicable

variación
Porcentaje efectivo del

torotoreptecto"

$\begin{array}{llc}40-41 & 54.0 & 54.0 \\ 41-42 & 55.6 & 54.8 \\ 42.43 & 57.2 & 55.6 \\ 43-44 & 58.8 & 56.4 \\ 44-45 & 60.4 & 57.2 \\ 45-46 & 62.0 & 50.0 \\ 46-47 & 63.6 & 58.8 \\ 47-48 & 65.2 & 50.6 \\ 48-49 & 66.8 & 60.4 \\ 49-50 & 68.4 & 61.2 \\ 500 \text { mis } & 70.0 & 60 \text { más }\end{array}$

Nota: Para los efectos de aplicar el sobreprecto, los porcentajes genalados aumentaran o disminuirán con el aumonto o disminución en el oobre refinado entregado ya que la escale anterior estŕ zeferids al promedio de ceutos de las empresas en 1968 y 1969. 
septiembre de 1969 se había completado el $62 \%$ de la inversión total prevista. (Véase el cuadro II-74).

\section{a) Convenio con lo Braden Cooper Co.}

El canvenio estabiece la asociación del gobierno de Chile con fa Braden Copper Co., f̣ilial de la Kennecott Copper Co., para formar la Sociedad Minera El Teniente S. A., que tomó los bienes, derechos y obligaciones y el activo y pasivo de la compañia norteamericana siendo, en consecuencia, su continuadora legal. Para estos efectos, Kennecott vendió a Chile el $\mathbf{5 1 \%}$ de las acciones de Fl Teniente en un valor de 80 millones de dólares.

La nueva Sociedad' está efectuando inversiones por más de 230 millones de dólares para aumentar la capacidad de producción de El Teniente de 360 millones de libras de cobre fino al año a 560 millones. Esta mina es en la actualidad la explotación subterránea más grande del mundo. Además se consideran mejoras en las instalaciones productivas existentes y en las condiciones habitacionales de empleados y obréros.

El programa de inversiones serrá financiado con los siguientes préstamos a la Sociedad Minera El Teniente, todos a 15 años plazo y con un interés de $53 / 4 \%$ anuales: i) 80 millones de dólares de la Braden Copper Co., cantidad que dicha empresa recibe como pago de la Corporación del Cobre (CODELCO) por el $51 \%$ de sus acciones de la nueva sociedad; i1) 27 millones de dólares de la coperco, y 12743000 adicionales de la Braden Copper Co. A las operaciones anteriores se agregan créditos del Eximbank, con aval del gobierno chileno, por la cantidad de 116016000 dólares.

Como sociedad mixta, la Sociedad Minera El Teniente está afecta a una tasa del $20 \%$ sobre su renta imponible; además, se gravan con el impuesto adicioníl de $30 \%$ los dividendos que corresponden a Kennecott (48\%) y que se retiren det pais.

CUADRO II-74

CHILE: INVERSIONES PROGRAMADAS Y REALIZADAS EN LA MINERIA DEL COBRE AL 30 DE SEPTIEMBRE DE 1969 a/?

(Millones de dólares)

\begin{tabular}{lccc}
\hline & $\begin{array}{c}\text { Total } \\
\text { programado }\end{array}$ & $\begin{array}{c}\text { Total } \\
\text { invertido }\end{array}$ & $\begin{array}{c}\text { Avance } \\
(\%)\end{array}$ \\
\hline Sociedad Minera El Teniente & 237.1 & 158.7 & 67 \\
Gnile Exploration Co. & 121.0 & 98.6 & 81 \\
Andes Copper Mining Co. & 11.8 & 11.1 & 94 \\
Compañfa Minera Exotica & 43.7 & 35.3 & 80
\end{tabular}


ubicado en la provinctio de Aconcagua, en el extremo sur del valle del Fío Blenco, a una altura de 3600 metros sobre el nivel del mar y en él existen 110 millones. de toneladae métricas reconocides do mineral con una ley de $1.6 \%$.

La explotactón de este mineral significará inversiones por 157 millones de dó lares que se timancian con 95 millones costeados con empréstitos externos que con. trae Andina; 41 millones en préstamos de los socios y 21 mtllones en actones, to las cuales 6.3 millones son aportados por el gobierno de Chile y el resto por Cerro Corporation. El convenio estipula además, que la Empresa Nactonal de Flectriuldad entregara a esta empresa energía al precio de costo.

Ĺs sociedad Minera Anetina S. A. está afecta a un impuesto de categarfa sobre utirdades de $25 \%$ y , un $30 \%$ de impuesto adicional sobre los dividendos ze* portido en el extranjero; además, el Istado participa en el $30 \%$ de las utillada.

\section{d) Convenio eon Sagasca.}

En Febrero de 1969 se autorizó a la Corparación del Cobse para tormar con ba Continental Copper \& Steel Industries Inc., una socledad minera maxta que se denominara Compañta Anóntma Cuprifera de Sagasca S. A. Para este electo Co. DELCO comprs el $25 \%$ de $2 a s$ acciones de dicha soctedad.

IA objeto soctal será la exploración, prospección, investigación, construcctón preparactón y puesta en marcha del mineral de cobre denominado Sagasca, quo se oncueatra ubicado on lia provincia de Tarapacá, asf como ta exploracion, producción y comercialización del cobre y otros metales no ferrosos, actividades que desarrollard dentro det regimen de mediana minerta.

\section{3.- It politica the "nactomalizacion pactuda".}

A fithes Juaro de 1969, el Gobletno de Chille convino con el grupo nortesmo:

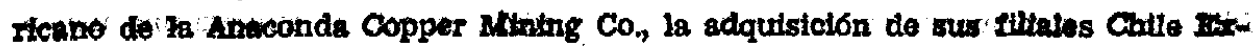
ploration Co. y Andes Mining Copper Co., sobre las baves que se rosumen a cantiviactón:

4) A partir del 19 de crero de 1970 se constituryen dos socledindes mineras mixtas a las cuales Chilex y Andes aportarán la totalidad de sus respectives activon y pastuces incluteas todas pertenenctis mineres de los yacimietto Chuquica-

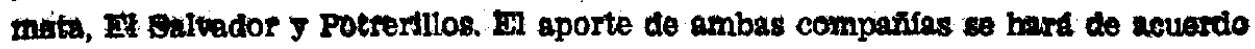
con el vilor quie tengan el actívo y pasivo en los balinces y lobros de esas um. frestas al 81 do Diciendive de 1968, ajustados il 31 de Diciembro de 1969, dentwo wel curteo normal de lax operaciones y constraccion, es dectr, sumando y restando

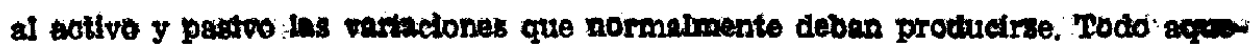
llo que tio corresponda $a$ in giro normal requerirc acuerdo de ambas parte pare str doductide o egroguda. 


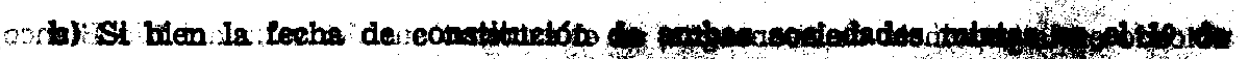

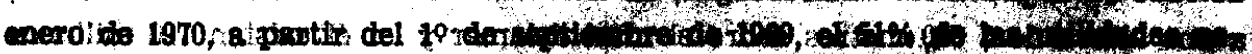

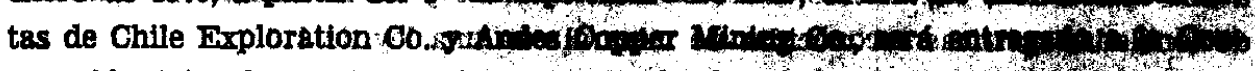

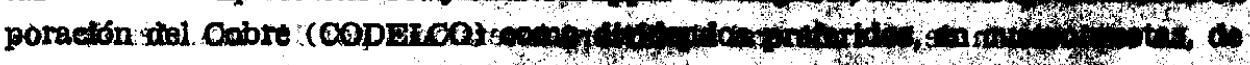

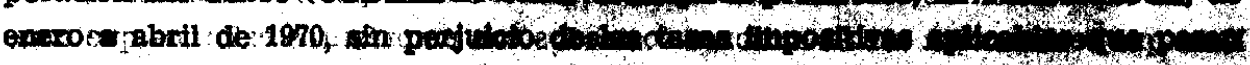

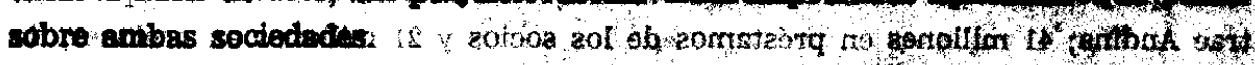

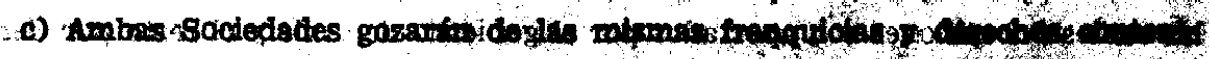

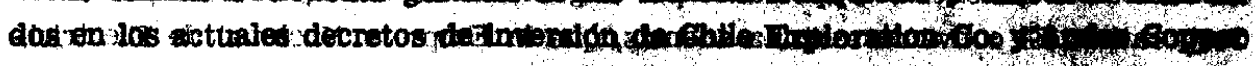

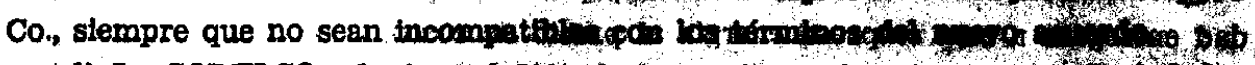

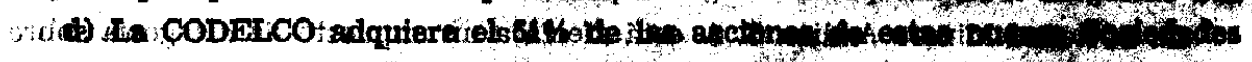

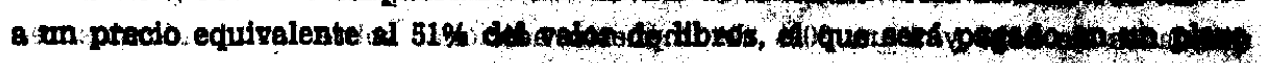

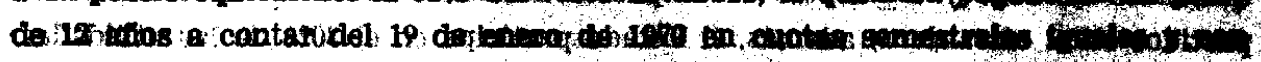
un interés del $6 \%$ anual sobre el saldo insoluto. Wl valor de $17 r_{0}$ of $61 \%$ \%

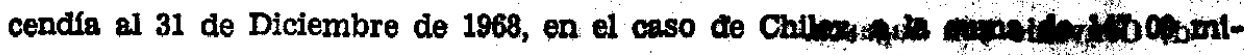
llones de dólares y en el de Andes, a 48.60 millones. Dichas clína dopm er ac-

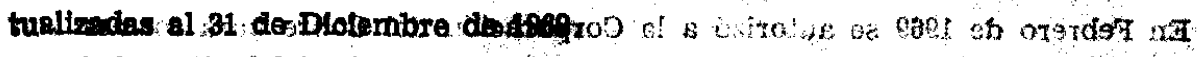

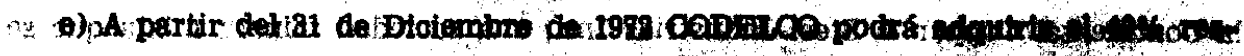

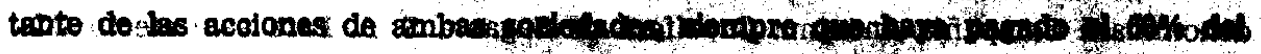

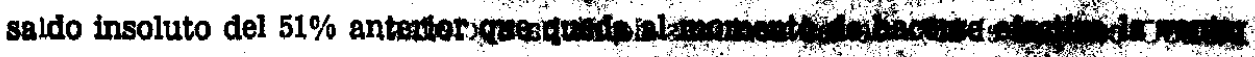

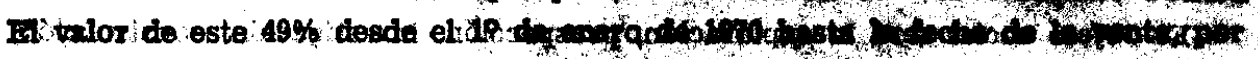

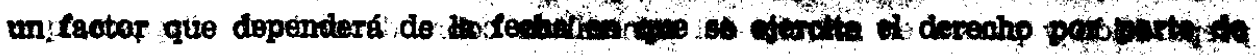

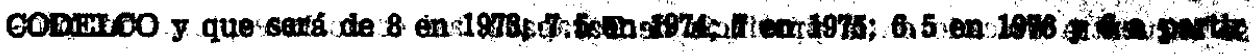

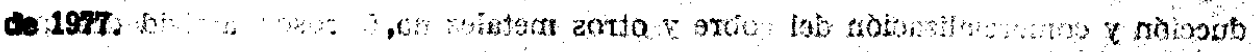

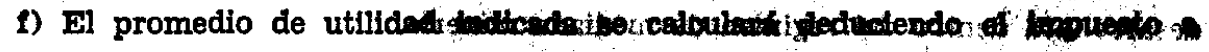
la renta, el impuesto adicional y la participación en el sobrepecio, con lo cual so.

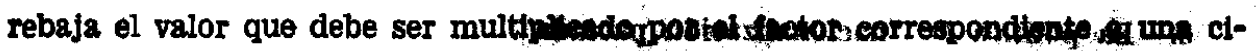
fra que jamás podrá exceder el $23.32 \%$ del total de las utllidades de la socledad

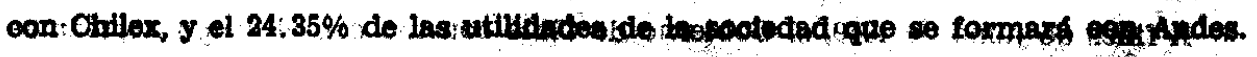

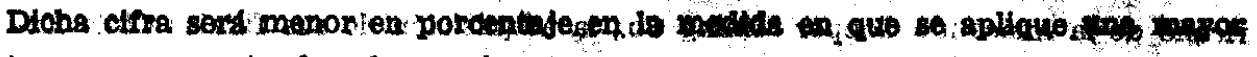

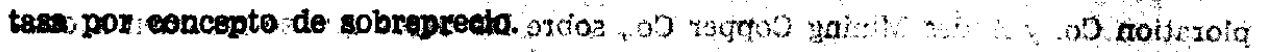

g) In pago del valor del $49 \%$ se hará en cuotas semestrales iguales Anthpfin

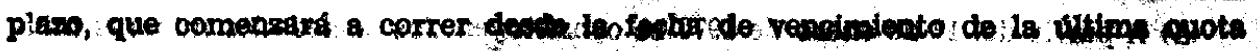

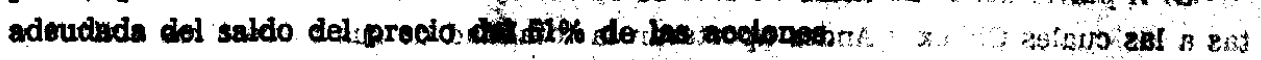

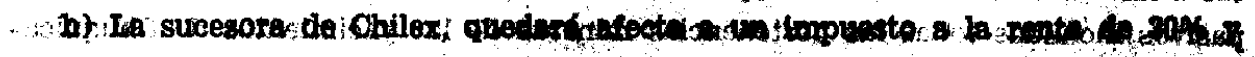

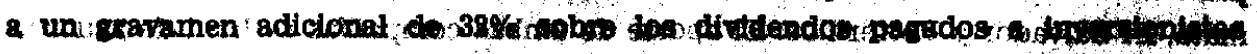

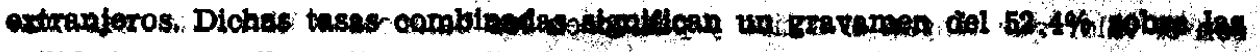

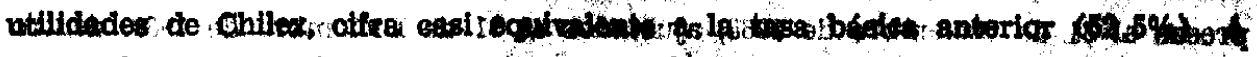

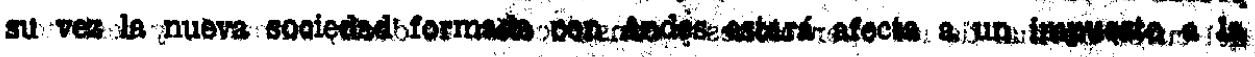

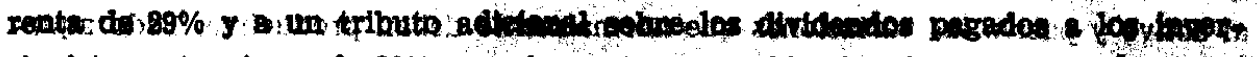

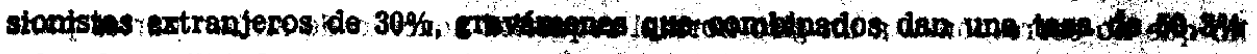

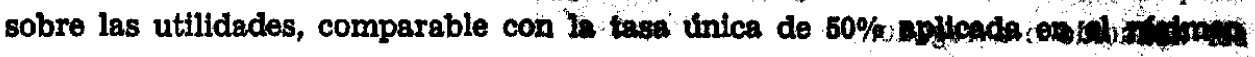
anterior. 
i) Este régimen impositivo es solamente aplicable cuando a costos constante en relación con al promedio 1968-69, el precio sea inferior a 40 centaros de dátar la libra, ya que a partir de este precio la participación del Fstado aumenta por concepto del dividendo acumulativo y preferente aplicable al sobreprecio, on formm progresiva, como se indica en el cuadra II-72, el que las nuevas sociedades establecerán en tawor de la Corporación del Cobre.

j) Las Sociedades serán administradas por un directorio compuesto por siete miembros titulares y siete suplentes. Las acciones de la Serie A, de la Corporacín del Cobre, eligirán cuatro directores titulares y cuatro suplentes y las de la Serie B yde las empresas extranjeras, tres titulares y tres suplentes. FI directorio estar encargado de la marcha de la Sociedad, de impartir directivas e instrucciones, ftw jar la polftica de comercialización, determinar precios y modalidades de venta designar a los ejecutivos de las Sociedades. Sin embargo, el Cerente, Subgerenta de Operaciones y Superintendente General serán nombrados y removidos por al directorio a propuesta de la Empresa Asesora que en este caso podrán ser Chilex - Andés $y$ par el plazo de vigencia del contrato de asesoramiento que aurará tres afos.

Tódos los actierdos de directorio serán aprobados por la simple mayoria de sus miembros, salvo algunos acuerdos de tipo general que requieren el voto favorable de uno de los directores de la Serie B. Fstos acuerdos se refieren fundar mentalmente a la enajenación de bienes raices, a la exploración y explotación de atros yaximientios mineros, a la emisión de bonos, al nombramiento del Preait dente, Vicepresidente, Gerente General y Contralor y a la transferencia te acciones, todas materias que en general coinciden con las atribuciones que tiene la Corparación del Cobre como socio minoritario en otras Sociedades Mixtas.

k) Existirn un contrato de asesoramiento entre las nuevas sociedades mixtas y las Compafifas Chilex y Andes $u$ otras subsidiarias, mediante el cual, éstas apottarán todos sus conocimientos y tecnologia en los diversos campos de la openbción y administración para la dirección técnica y de operación de los yacimientos nuevos aportados y de los establecimientos, faenas y servicios anexos. El contrato de asesoramiento abarca la operación de plantas, la administración y las ventas. Los honorarios se estipuan en una suma equivalente al $1 \%$ del total de las ventas de la Sociedad, considerando como precio máximo 60 centavos de dólar la libra y la duración será hasta el 31 de Diciembre de 1972, pudiende en todo caso, la CODELCO poner término al contrato a partir de esa fecha, siempre que hubiere pagado "Chllex o Andes el $60 \%$ del saldo insoluto del $51 \%$ de las accionts de las respectivas socledades mixtas.

4.- Valores retornados y no retornados.

Si se examina la evolución que han tenido los diferentes renglonas que conforman los valones retornados al país por concepto de las exportaciones de cohre 


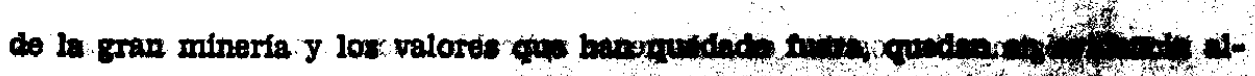

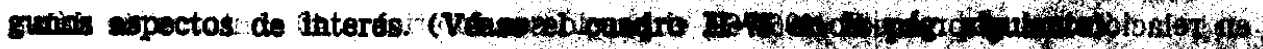

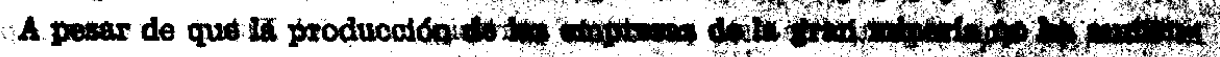

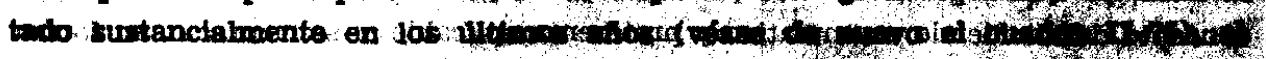

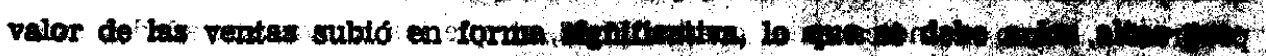

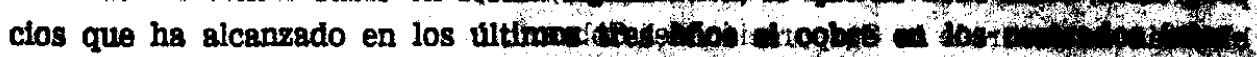

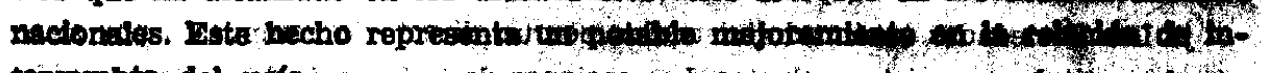

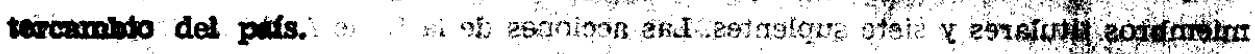

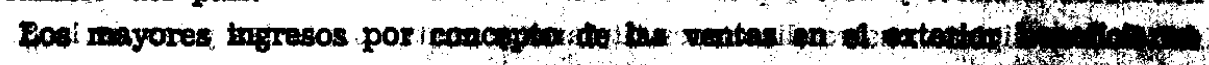

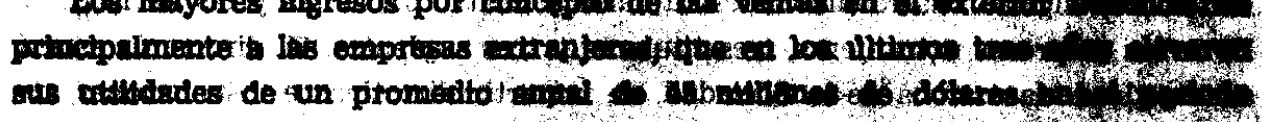

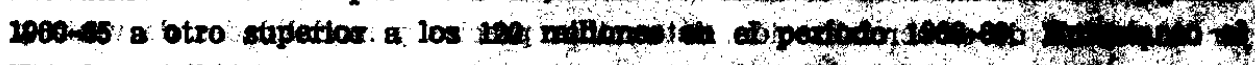

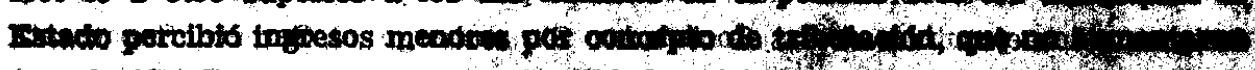

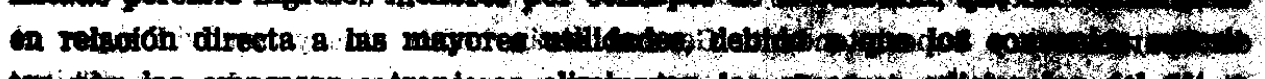

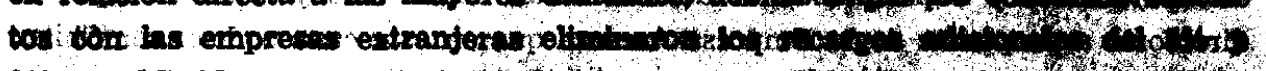

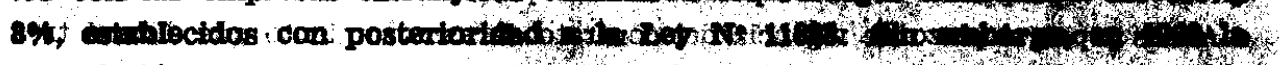

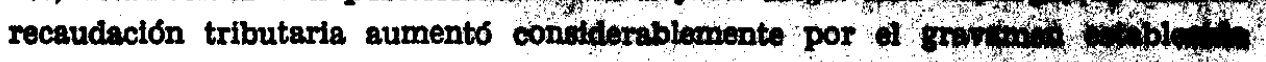

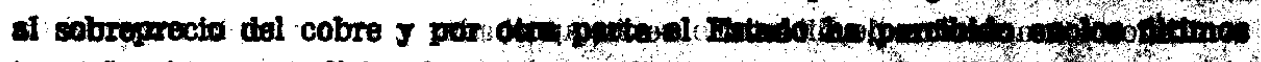

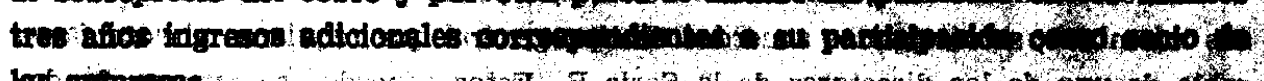

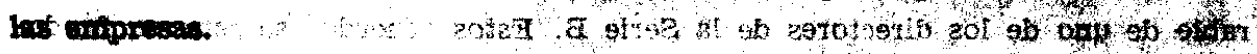

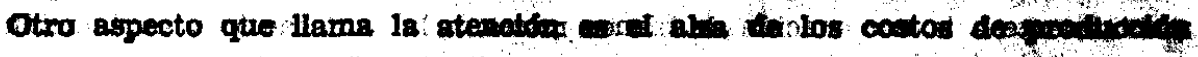

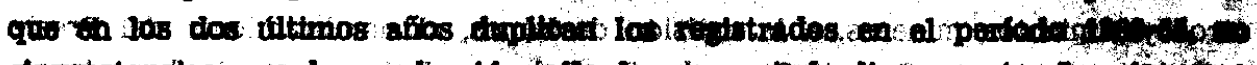

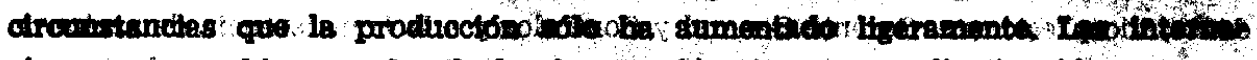

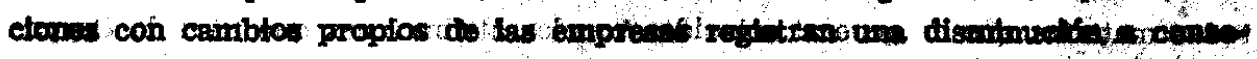

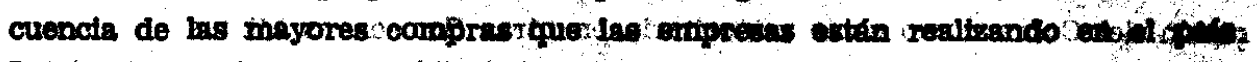

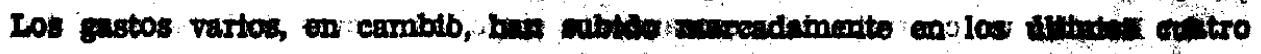

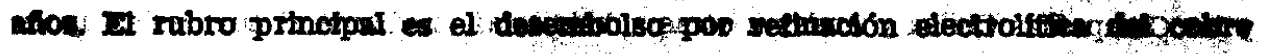

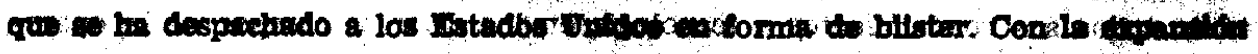

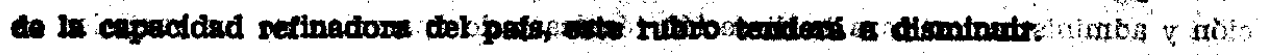

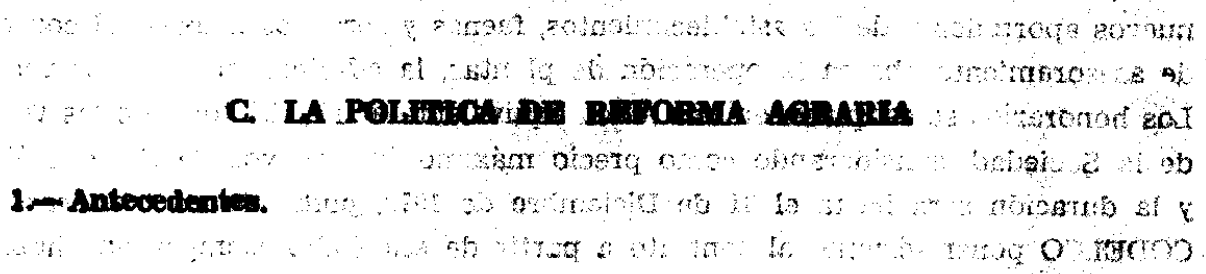

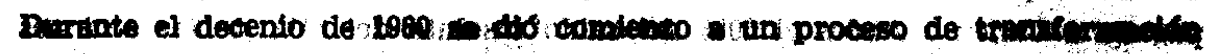

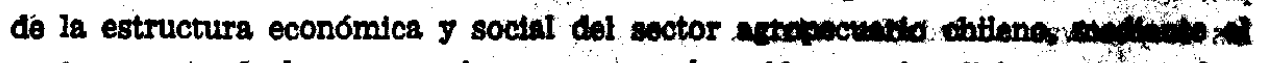
cual se pretende lograr, gracias a una reasignación y más eficiente aptoveoha-

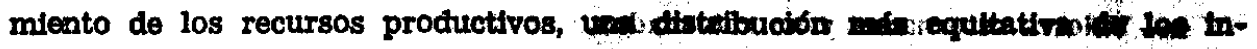
gresos que se generan en el sector, un aumento de la producolon sgopeneanria

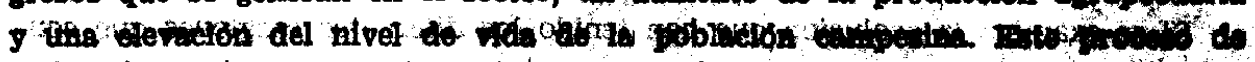

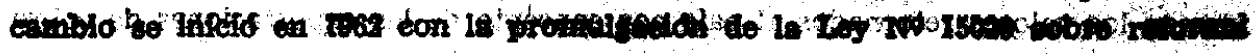




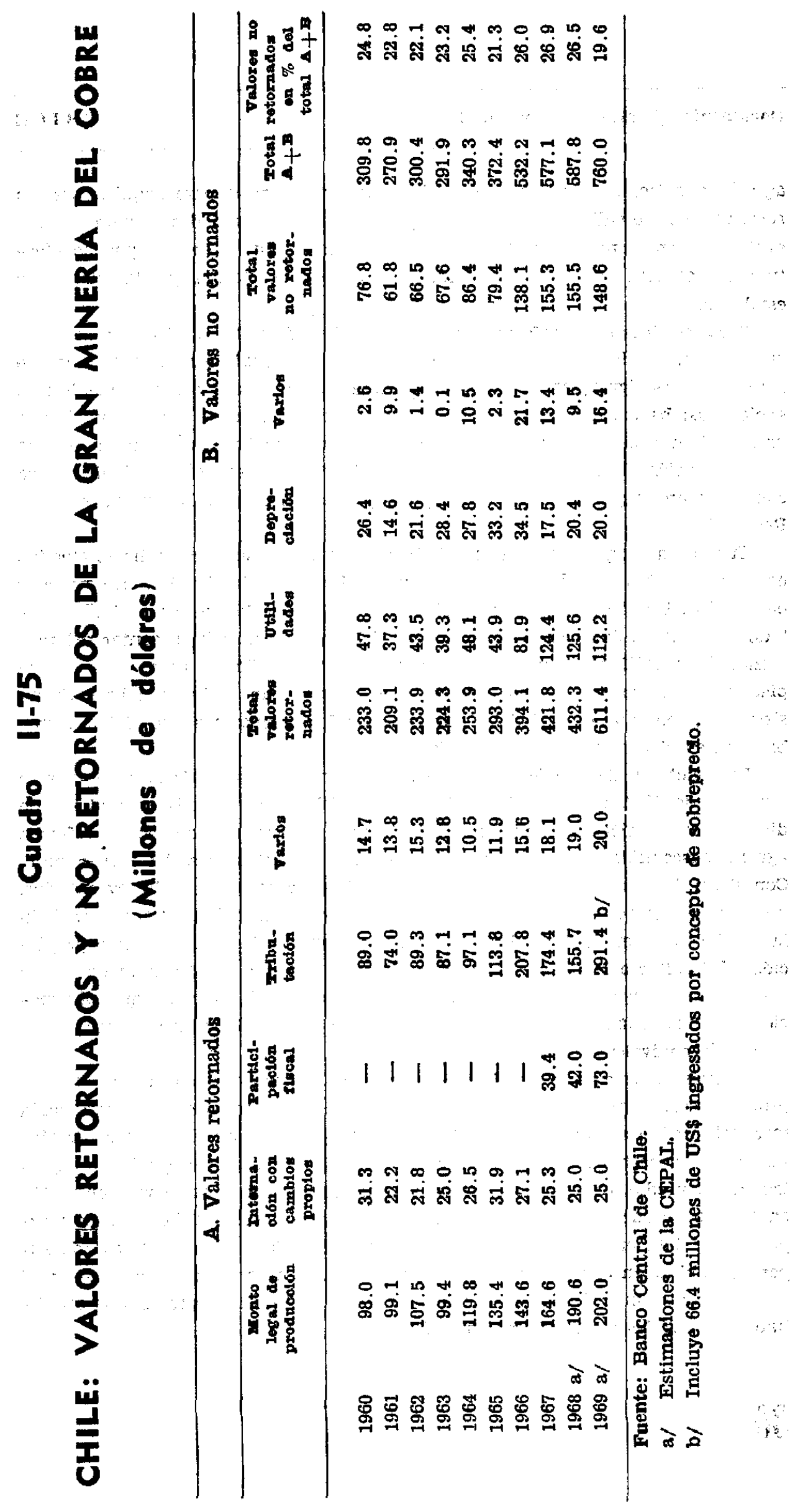




Documentos / Informe Cepal 1900

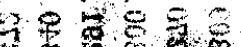

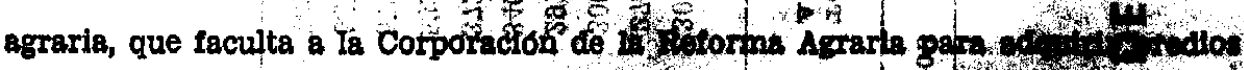

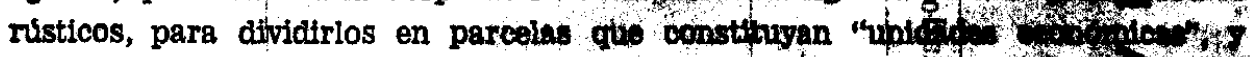

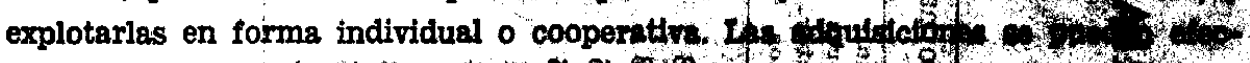

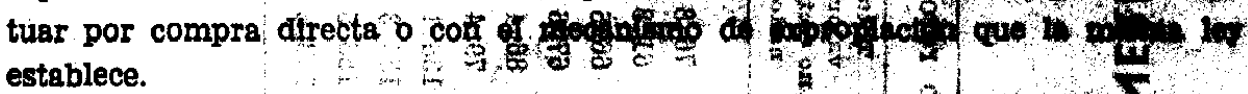

Para los fines de la reforma agraria, se declaró de utilidad publios y tw anto-

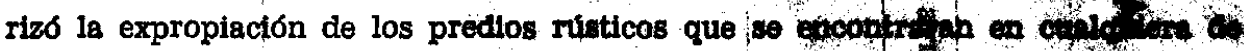

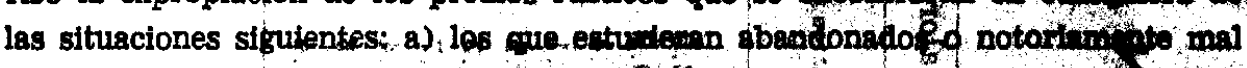

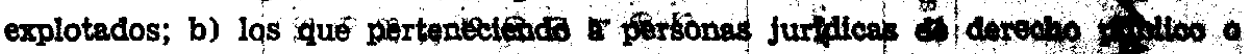
privado fueran explotados en cualquiera torma que no fuem tirectar of $p \mathrm{p}$ que la Corporación de la Reforma Agrarla considerara indippensable oflow pap

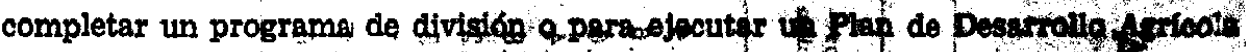
Reglonal. 30 .

Cuando las adquisiciones se realizaban por compra, su paco so truth flectwo

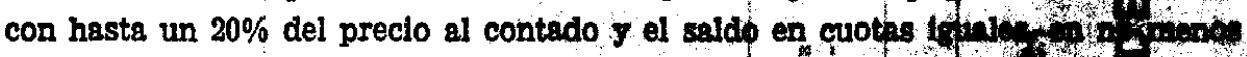

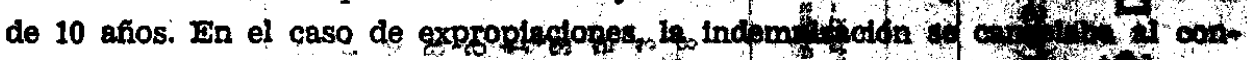

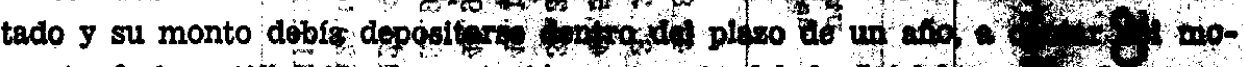

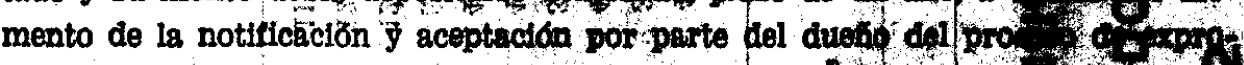

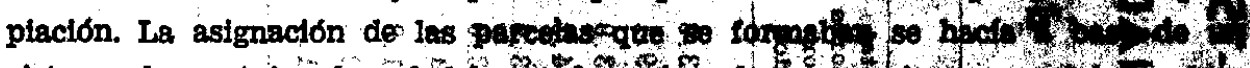

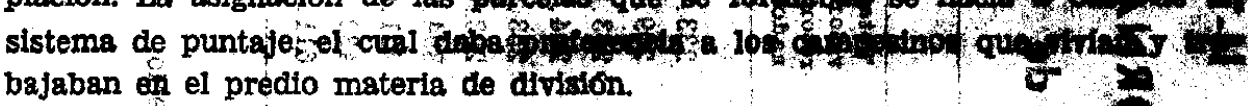

La aplicación de esta ley, que estuvo en vigencia hasta el término dónoxíngr semestre de 1967, no obstante contener disposidiones de interes mis m

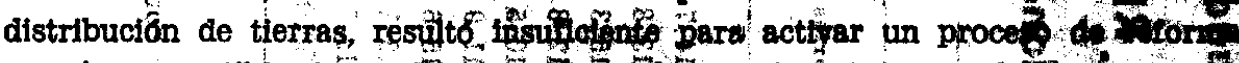

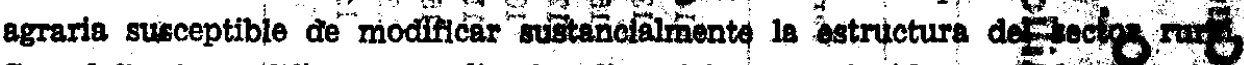
Con el fin de modificar y ampliar las disposiciones contenidas en 5 tort torior. y hacer más expedita e intensw la incorporación y distribución de tierras, ste dictó la Ley $N$ o 16640 en Jullo de 1907 L

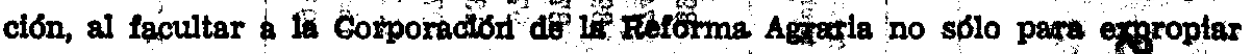
los predios abandonados o mal trabajados, sinó además aquellos que Artoneclendo a una misma persona natural excedieran de 80 hectsreas de riecibo una superficie equivalente.

Adem, se establecio que la Indeminiacion a favor del dueño del priso exproplado sería equivalente al avalúo vigente para los electos de la con pución $^{-}$ territorial más el valor de las mejoras existentes no comprendidas en el pario. La forma de pago de esta indemnizgoion debia diferit seguis el grado otoxplo-

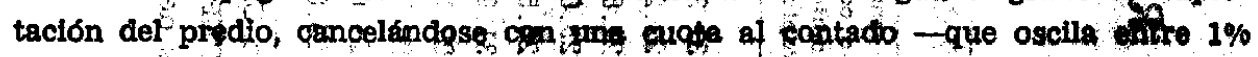
en el caso de encontrarse abandonado, el $5 \%$ en los predios deficientemose explotados y $10 \%$ en aquellos cuyas causales de expropiacion sea el excend 40 superficie, ubicación estratégica dentro de una zona de reforma agraria, etco, y el saldo, hastw en un máximo de 30 anga en enonos de raforma agraria, quéfon titulos reajustables y con un interes de $8 \%$ anual.
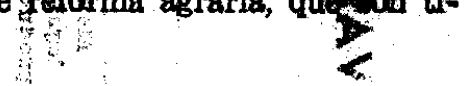
Una dispostotón nueva, contenida en la ley de reforma agraxia de 1967, se roflere a las mercedés de agua: Mediante ella se declararon expropiabjes tos derechos de agu pertenecientes a particulares, quedando su reaslgnación postanidr en manos del Estado a través de organismos creados expresamento para el efecto.

Enumeradas algunas de las principales disposiciones legales que han enmarcado el proceso de reforma agraria durante este decenio, se tratará de cuantificar, a base de determinados incicadores, los avances que se han realizado tanto en la incorporación y distribución de tierras, como en lo que se refiere a las inversiones que ha significado todo este proceso.

Zn los prthieros anos 01963 y 1964), los avances del proceso de verotma fueron limitados, principalmente porque no se efectuaron expropiaciones y las únicas therras que se incorporaron fueron aquellas adquiridas por la CORA mediante transaeciones de compra directa: En el heeho, la superfieie comprada a particulares durante esos años no superó las 20000 hectáreas. Por esta razón, el análisis se concentrará en el quinquenio 1965-69, cuando el proceso de reforma adquiere mayor envergadura y dinamismo.

\section{2-Incorporacion de tierras.}

Durante el perído comprendido entre 1965 y 1969 se han incorporado al proceso de reforma agraria, 1118 predios con una superficie total de 2871500 hectáreas, de las cuales 249000 son de riego y 2623000 de secano. En esos predios vivian 17390 familias en el momento de la incorporación, número que ha aumentado a más de 20000 después de organizados los asentamientos. De la informad6n del cuadro II-76 se deduce que-la cantidad de predios incorporados crece considereblemente atre ol primero y segundo año del quinquento (99 predies on 1965 y 265 en 1966), se reducen en los dos años siguientes, aunque su número se mantiene alrededor de ilos 220 predios, y sube a más de 300 en 1969 .

La superficie total que corresponde a los predios que se incozporaron en cada ano se mantien sobre les 500000 hectáreas en 1965-66 y disminuye sonsiblemente en 1967. Sia embargo, en los años 1968 y 1969 el área total creoe con rapidat superando las 860000 hectíreas en el último año mencionado. (V́́ase et cuadwo II-76).

Ia evolución que observa en la superficie total, así como su compor sicion, han dependido del número de predios que se incorpozan cade año de ila extensión que tienen y de le calidad de sus tierras. En este sentido, la reducción del año 1967 está inđaicando que, comparativamente con otros años, jos predios que se incorporaron ese año fueron de menor extensión. En efeeto, la superficie media resulta la más haja del período y alcanza a 1300 hactíreas, aunque in proporción de la superficie de riego sube a $18 \%$. In año 1965 omurrio lo opuesto, ya que los predios que se incorporan tenían una superficie promedio que alcanzaba a 5500 hectáreas y es la más elevada del quinquenio. Esto se debió a la transferencia de predios que pertenecian a điversos organismos del sector pú- 


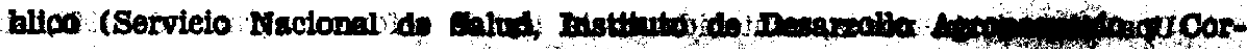

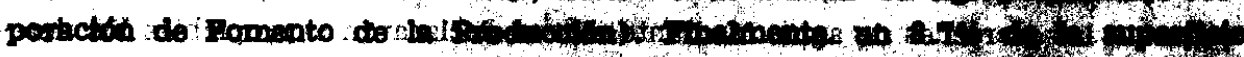

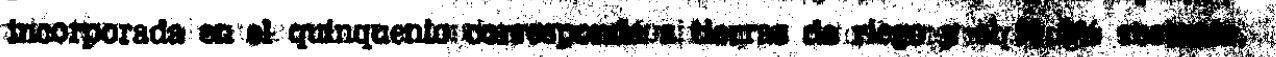

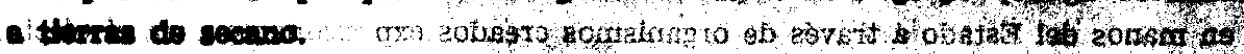

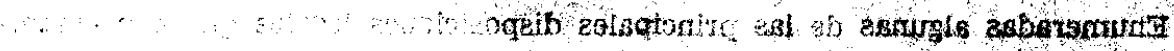

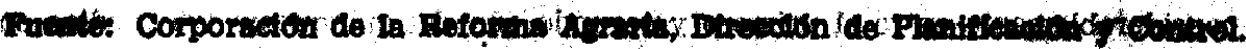

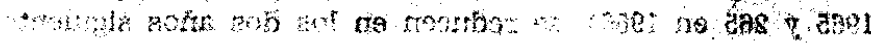

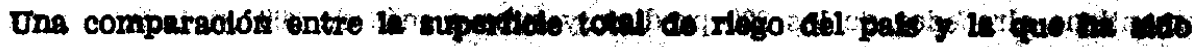

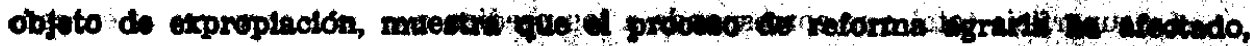

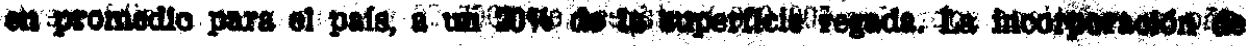

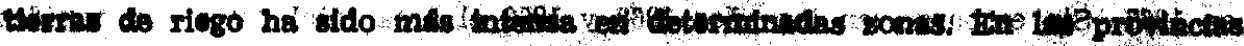

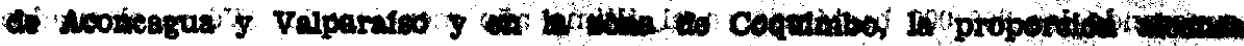

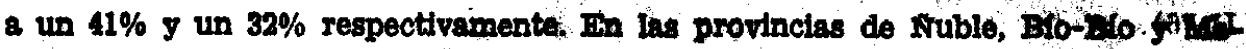

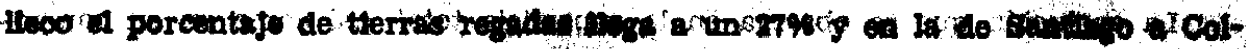

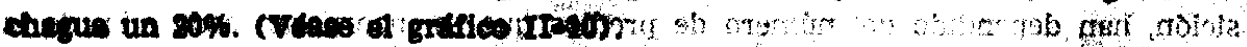

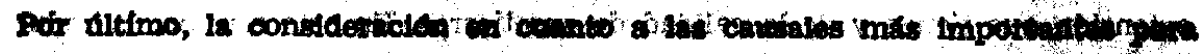

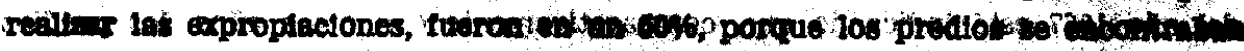

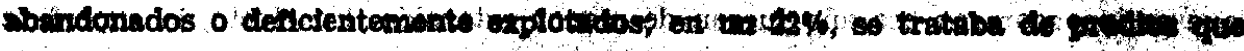

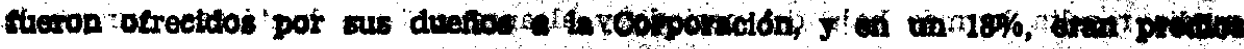

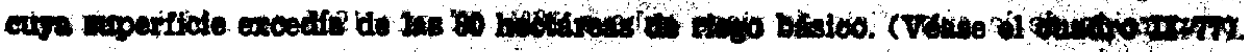

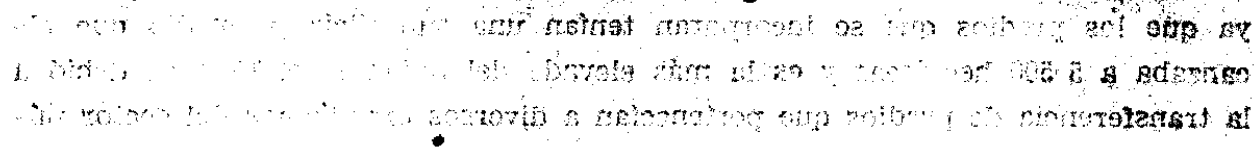




\section{CUADRO II-77}

CAME: CAUSALES DE ENAIENACION DE TIERRAS

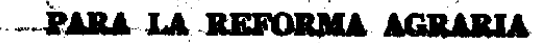

\section{Angropisciones}

Predios abandonados 0 mal explotados

Predios ofrecidos por sus duefios a la Corporación

Predios cuys superficie excede de 80 há de Riego Básico Predios de propiedad de personas jurídicas de derecho ptiblico o privado

Unidades de superficie igual a 80 há de Riego Básico

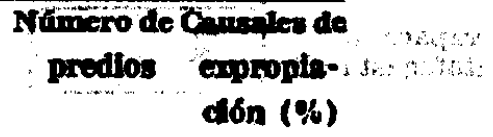

Unidades resultantes de la división de un predio de superticie superior a 80 há de Riego Básico, cuya división se haya efectuado con postexioridad al 4 de Noviembre de 1964 y no se haya hecho materialmente efectiva

Subtotel

Otras fuentes de obtención de tierras

Transferencias fiscales, adquisición a particulares y fiscales, fundos en administración, parcelas vacantes de colonias constituidas

Total predilos

1118

$\begin{array}{ll}541 & 50.1 \\ 241 & 22,3 \\ 197 & 18,2\end{array}$

40

3.7

$16 \quad 1.5$

$1000 \quad 100.0$

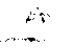

Puente: Corporación de la Reforma Agraria, Informas de expropiación.

3.- Formación de asentamientos y asignsción de prediea.

Ia primerc etapa en el proceso de distribución de tierras he cida is formación de 108 llamados asentamientos campesinos. Durante un porlodo de hasta tres afos y que en determinados casos se extiende a cinco, lai-utivis won explotadas por la Corporación de la Reforma Agraria y los asentados, formando Sociedades Agrfcolas de Reforma Agraria. La finalidad de esta etapa es capacitar a los asentados para que asuman plenamente las responsabiliciades do 
.

PORCENTAJES

TT-II ORanuo

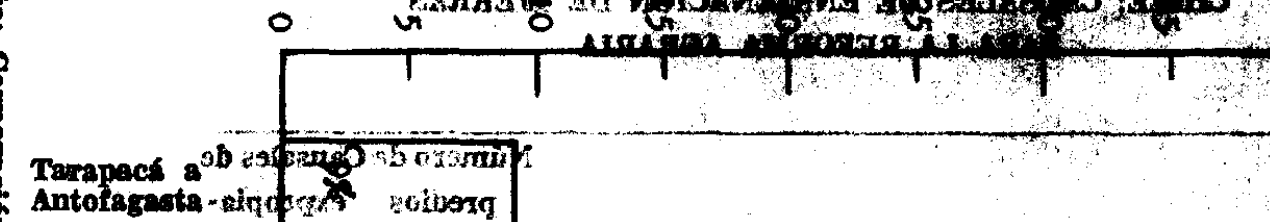

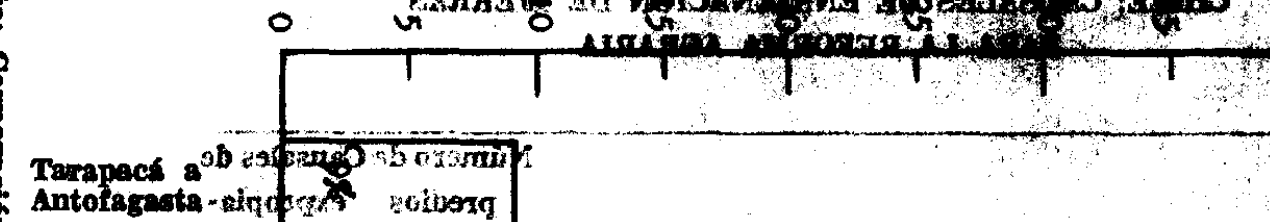

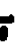

Atacama a

(4) ) tô

Coquimbo

(1)

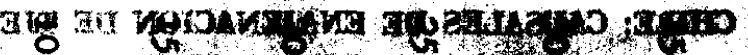

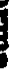

Aconcazua a

Valparatio

Santiago

O'Higgins a

Colchagus

W

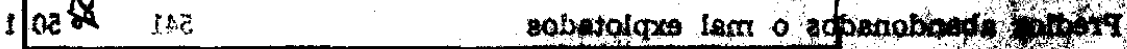

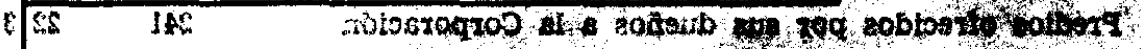

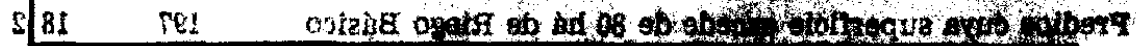

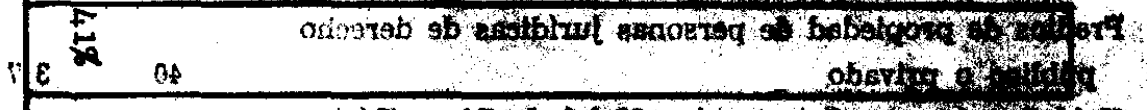

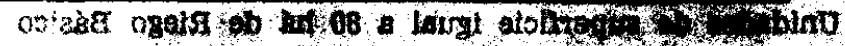

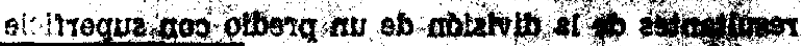

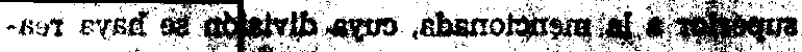

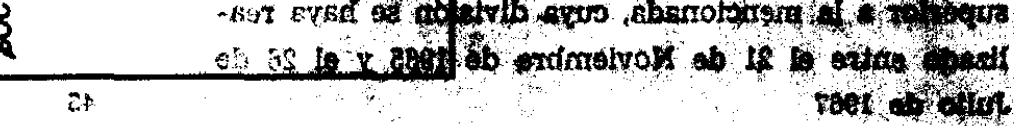

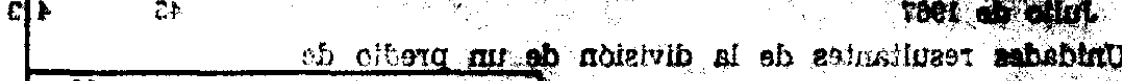

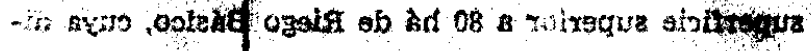

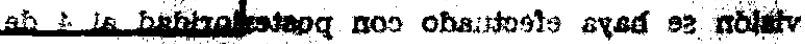

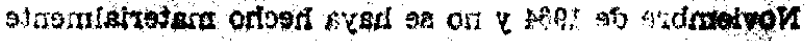

Curico a

Talca

i.

定

switopts

latojotue

Linares a
Maule

Nuble

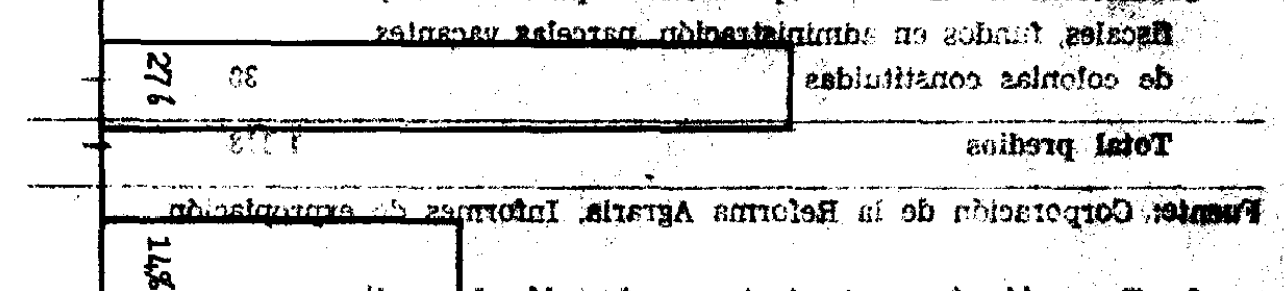

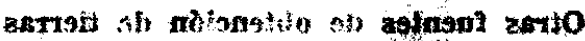

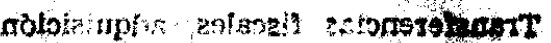

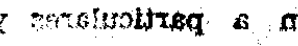

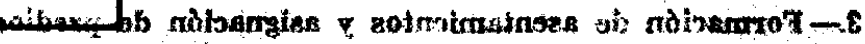

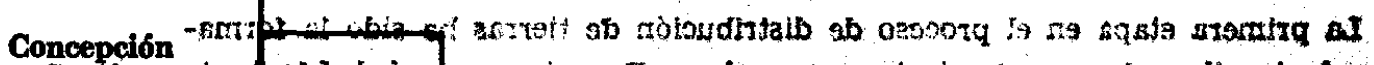

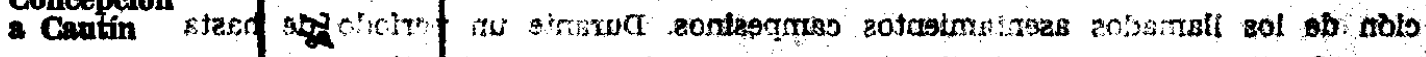

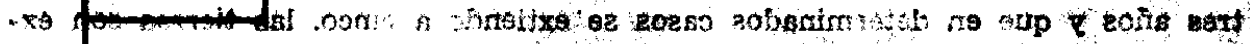

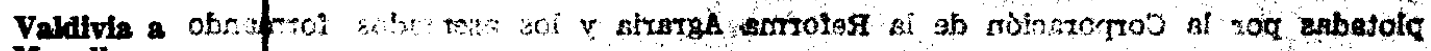

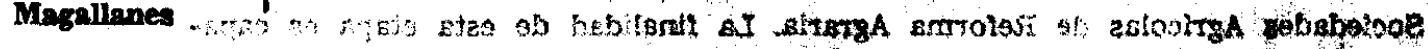

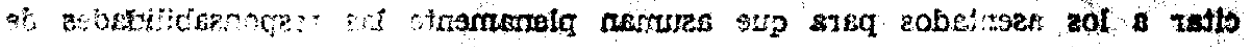

(i) 
propietarios y de empresarios agricolgs, junto con permitir la realización de obras do infraestructura y de cepitalización necesarias para desarrollar la actividad agricola eficientemente.

Un análisis de las estadísticas sobre formación de asentamientos en el quinquenio que sê colisidef trevela (vease el cuadro II-78) que" en el periodo se ha formado un total de 633 asentamientos, que trabajan una superfigie de 2600000 hectáreas; siendo do riego poco mas de 203 og9 y de secang 2 387 . 000 . El pnoceso de formación de asentamientos ha tenido un ereoimiento constante, comenzando el año 1965 con ia constitución de 33 asentamientos hasta alcanzar en el año 1969 un número de 229.

CUADRO II-78

GHIT: FORMACION DE ASENTAMIENTOS

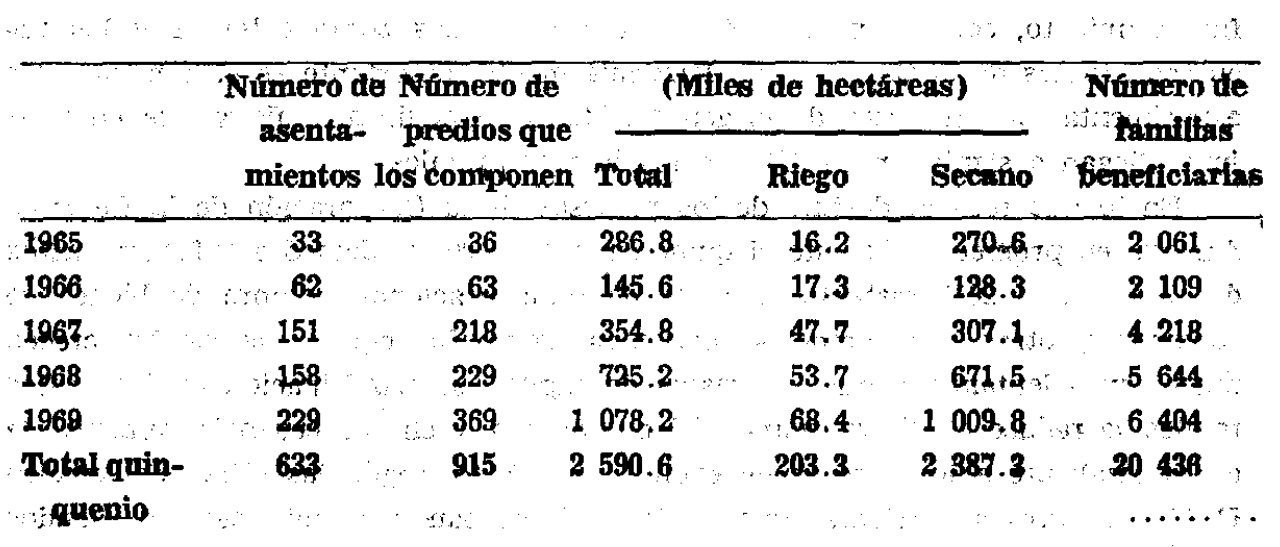

Fuente Corporación de la Reforma Agrarla, Dirección de Plantilcacfón y control.

Una comparación entre el número de predios en los cuales se han constituido asentamientos y el total de predios expropfadós permite deducir que en un $82 \%$ de los predios incorporados en el período se había iniciado su etapa de asentamiento.

Como se anotó antes, el número de famillás beneficiadas con la reforma agraria alcanzaba a fines de 1969 a poco más de 20000 . La superficie medis por tamilia asentada alcanzó en el período a 10 hectáreas de riego y 117 de secano. A despecho del incremento en el número de familias favorecidas, el total quedó bastante lejos de las metas señaladas en círculos oficiales al iniciarse el proceso, cómo también del objetivo manifestado por el Ministro de Hacienda en su exposición al CIFS de Octubre de 1967 y en el cual, -debido a dificultades encontradas en 1965-66 en cuanto a financiamiento, mano de obra y ocupación de las tierras expropiadas - se indicaba que las metas para el período 1965 a 1970 serian entre un minimo de 40000 y un máximo de 60000 familias. 
4) Ec El mimero do asight

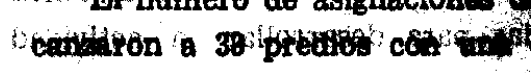

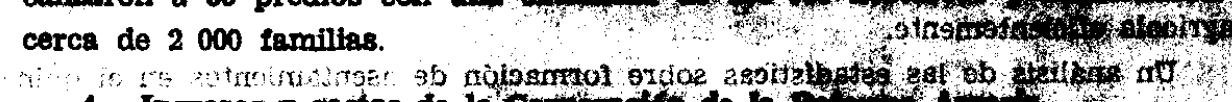

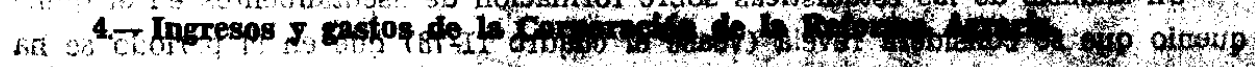

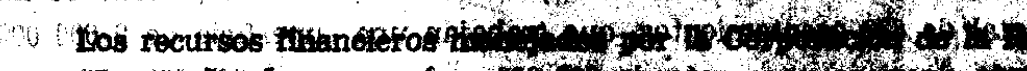

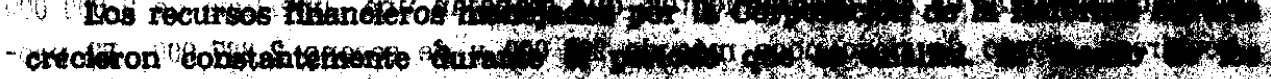

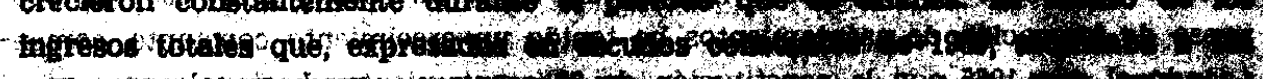

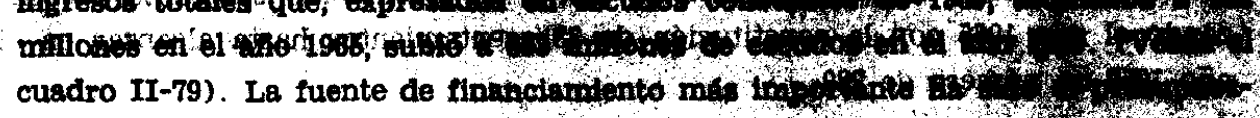
to nacional. Sin embargo, la importanda to ese rubro so ha ldo $\%$.

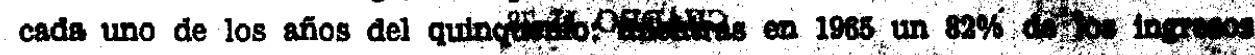

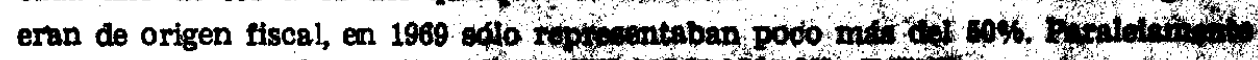

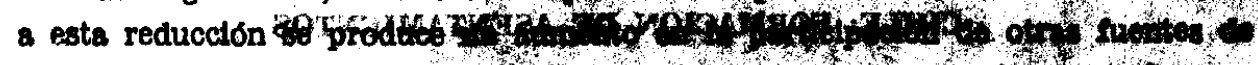

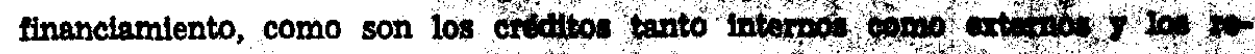

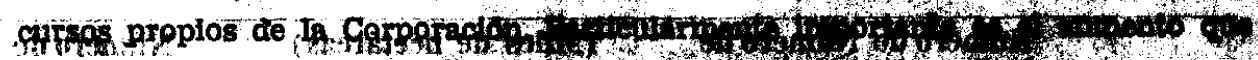

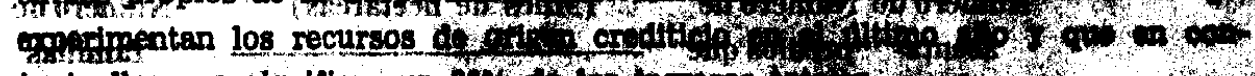

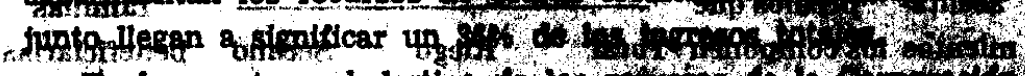

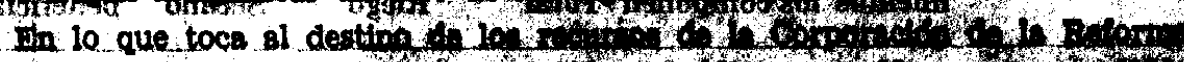

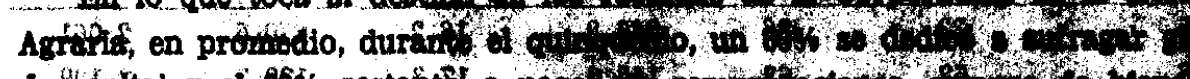

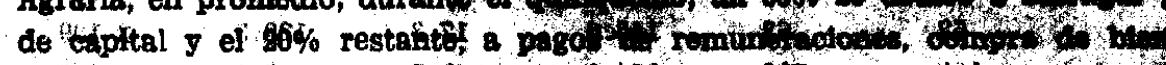

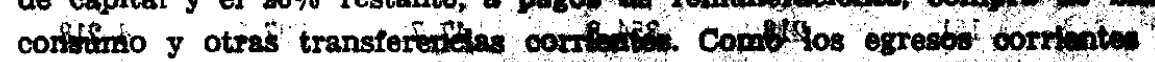

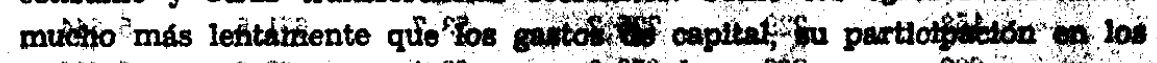

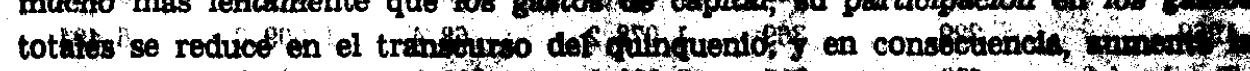

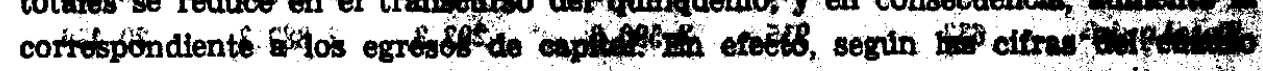

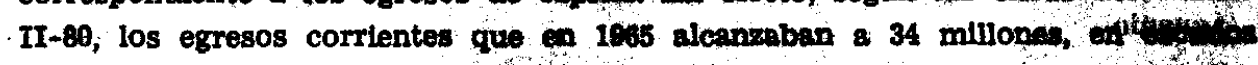

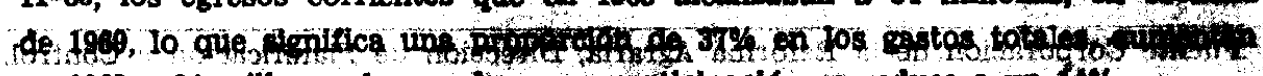
en 1969 a 94 millones de escude y va puticipación se reduce a un 1 \%

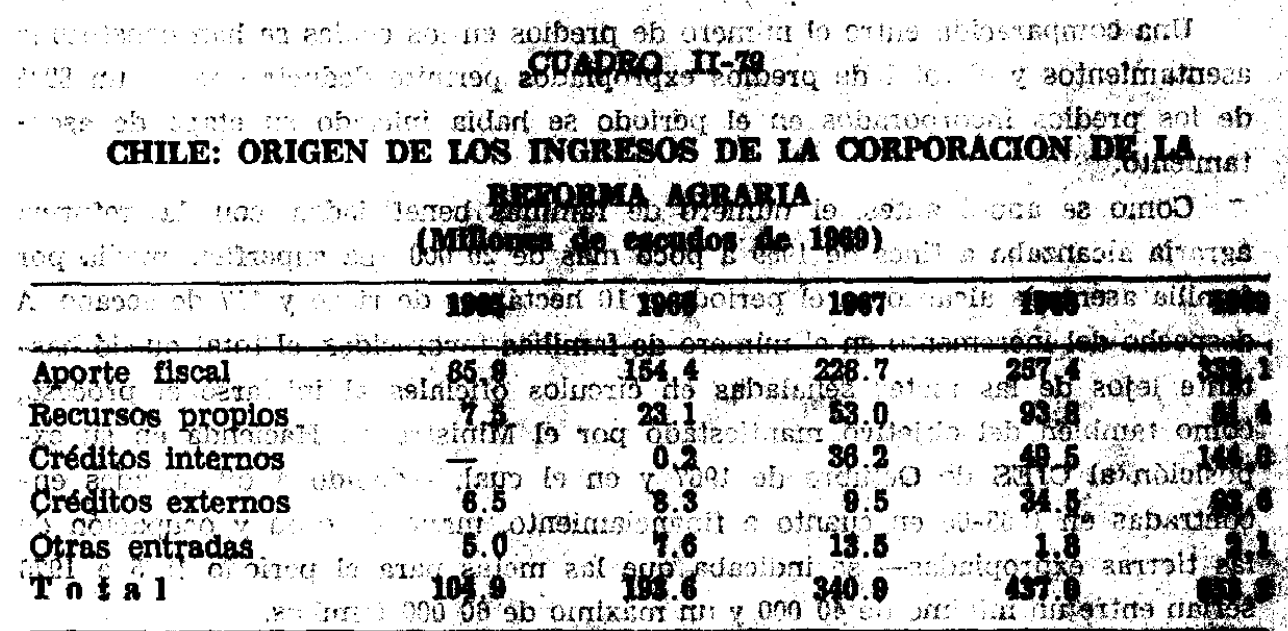

Fuente: Corporación de la Reforma Astaria: anos 1965, 1966, 1907, 1963, baladec; ano 1969: Presupuesto. 
CUADRO II-80

\section{CHILE: GASTOS E INVERSIONES DE LA CORPORACION DE LA REFORMA AGRARIA}

(Millones de escudos de 1969)

\begin{tabular}{|c|c|c|c|c|c|}
\hline & 1965 & 1966 & 1967 & 1968 & 1969 \\
\hline Egresos corrientes & 34.1 & 48.0 & 73.2 & 80.3 & 93.5 \\
\hline Remuneraciones $\ldots \ldots c c c$ & 18.3 & 25.3 & 37.1 & 48.5 & 54.1 \\
\hline \multicolumn{6}{|l|}{ Compra de bienes de consumo y } \\
\hline bienes no personales $\ldots \ldots \ldots$ & 11.8 & 18.1 & 18.5 & 11.9 & 18.4 \\
\hline Gastos de transferencias $\ldots \ldots$ & 3.6 & 4.6 & 17.6 & 19.9 & 21.0 \\
\hline Otros gastos $\ldots \ldots \ldots \ldots$ & 0.4 & - & - & - & - \\
\hline Egresos de capital & 59.0 & 138.5 & 259.2 & 354.3 & 559.6 \\
\hline Infraestructura $\ldots \ldots \ldots \ldots$ & 14.2 & 27.9 & 42.7 & 51.6 & 80.6 \\
\hline Adquisición maquinaria y equipo & 4.7 & 6.5 & 3.7 & 2.5 & 9,6 \\
\hline Adquisición de tierras $\ldots \ldots \ldots$ & 1.3 & 7.9 & 23.3 & 28.0 & 45.0 \\
\hline Compra de casas y edificios $\ldots$ & 0.7 & 1.5 & 1.0 & 2.4 & 5.3 \\
\hline Concesión de préstamos $\ldots \ldots$ & 26.7 & 74.9 & 164.9 & 224.8 & 333.0 \\
\hline Amortización terrenos adquiridos & 9.9 & 10.6 & 12.2 & 11.5 & 30.0 \\
\hline Amortización de créditos $\ldots \ldots$ & - & - & - & 21.2 & 40.0 \\
\hline Otros egresos de capital $\ldots \ldots$ & 1.5 & 9.2 & 11.4 & 12.3 & 16.1 \\
\hline Total de egresos & 93.1 & 186.5 & 332.4 & 434.6 & 653.1 \\
\hline
\end{tabular}

Fuente: Corporación de la Reforma Agraria, Dirección de Planificación y Control, años 1965, 1966, 1967 y 1968: balances; año 1969: Presupuesto.

Desde 1965 a 1969 las inversiones de capital crecen de 59 millones, en escudos de 1969, a 560 millones de escudos. El rubro más importante en la composición de estos gastos es la concesión de préstamos a los asentamientos campesinos. Su monto ha crecido de 27 millones de escudos (45\%) en 1965 a $333 \mathrm{mi}-$ llones en $1969(60 \%)$. Las inversiones en obras de infraestructura (caminos, viviendas, cercos, obras de riego, etc.), adquisición de maquinarias y equipos, compra de tierras y pago de indemnizaciones y compra de casas y edificios, cuyo monto en 1965 era de 21 millones, han aumentado hasta alcanzar en 1969 a 141 millones de escudos de igual poder adquisitivo. Otro gasto que era importante en 1965, la amortización de terrenos adquiridos, ha ido reduciendo su participación en el transcurso del quinquenio, de un $18 \%$ a algo más de $5 \%$ en el último año. La amortización de créditos comienza a tener significación solamente en los años 1968 y 1969 , cuando su proporción representa un $6 \%$ y $7 \%$, respectivamente.

Los gastos totales efectuados por la Corporación de la Reforma Agraria en relación con el número de familias asentadas en cada año dan un promedio por familia del orden de los 45000 escudos en 1965 y 32 000, en 1969, todo ello expresado en moneda constante a precios del último año. 
08-II OFurio

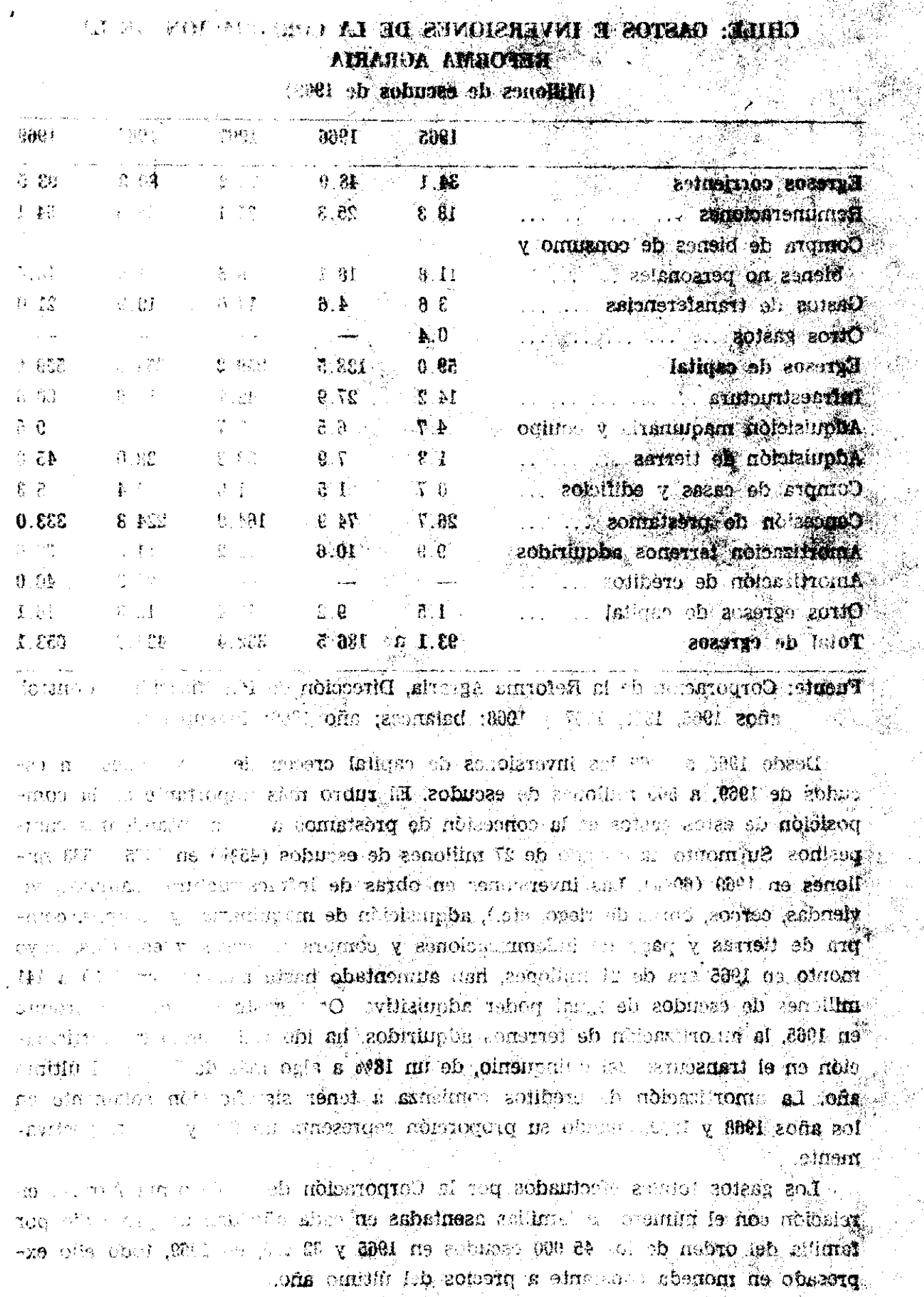

